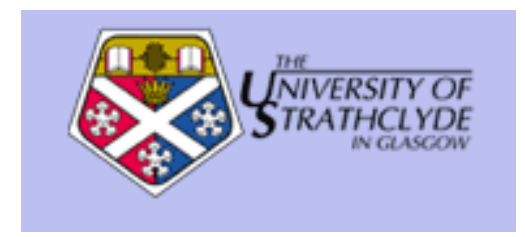

Hodge, C. and Stack, M.M. (2010) Tribo-corrosion mechanisms of stainless steel in soft drinks. WEAR . ISSN 0043-1648

http://strathprints.strath.ac.uk/20220/

This is an author produced version of a paper published in WEAR . ISSN 0043-1648. This version has been peer-reviewed but does not include the final publisher proof corrections, published layout or pagination.

Strathprints is designed to allow users to access the research output of the University of Strathclyde. Copyright (C) and Moral Rights for the papers on this site are retained by the individual authors and/or other copyright owners. You may not engage in further distribution of the material for any profitmaking activities or any commercial gain. You may freely distribute both the url (http://strathprints.strath.ac.uk) and the content of this paper for research or study, educational, or not-for-profit purposes without prior permission or charge. You may freely distribute the url (http://strathprints.strath.ac.uk) of the Strathprints website.

Any correspondence concerning this service should be sent to The Strathprints Administrator: eprints@cis.strath.ac.uk 


\title{
Tribo-corrosion mechanisms of stainless steel in soft drinks
}

\author{
C. Hodge and M.M. Stack \\ Department of Mechanical Engineering \\ University of Strathclyde \\ 75 Montrose St, \\ Glasgow \\ G1 1XJ
}

\begin{abstract}
$\underline{\text { Abstract }}$
Tribo-corrosion mechanisms of 316L Stainless Steel in slurries containing common household soft drinks have been studied through investigating the micro-abrasioncorrosion performance using a ball and disk apparatus which has been modified to measure the in-situ corrosion current during the abrasion process. The objective of this study was to evaluate the effect of $\mathrm{pH}$ and solution viscosity on the micro-abrasioncorrosion performance of the material. 316L Stainless Steel was selected because it is commonly used as a dental replacement material. This is an important area of work as the use of steel retainers as well as other stainless steel dental replacements is still widespread and the effectiveness of these devices will be determined by their tribological and tribo-corrosion performance. Additionally, an attempt has been made to investigate the importance of the $\mathrm{pH}$ and viscosity variables on the tribo-corrosive synergism, wastage and mechanism maps.
\end{abstract}

\section{Introduction}

"Every tooth in a man's head is more valuable than a diamond" Miguel de Cervantes, Don Quixote, 1605.

In recent years there has been a developing trend towards the use of advanced materials in the dental replacement industry. Examples include; Porcelain, Compomers, Composite Resins, Glass Ionomer cement and Zirconium Oxide. However, the use of metallic replacement materials is still widespread. 
An important area of work is in investigating the use of stainless steel for crowns and retainers as well as implants, a common scenario, especially in developing countries where the economic benefits of using stainless steel far outweigh the aesthetic performance and the slight toxicity risks [1]. The importance of tribo-corrosive synergy in Stainless Steel is also not limited to dental applications and the very same machines which produce the corrosive foodstuffs which we consume are also affected.

It has been shown that the average human set of teeth experiences between 15 and 30 minutes of contact loading per day which accounts for around $9 \mathrm{~cm}$ per tooth of sliding distance each day [2], a significant high rate given that the general expectation is that such replacement materials should last for years. To date, there have been over 1000 studies [3] on the performance of both human teeth as well as artificial replacement materials. The outcomes of these studies have led to the identification of a wide range of physical properties in such materials, including wear and corrosion resistance as well as hardness and fatigue characteristics.

There has also been a significant advancement in the techniques used to evaluate the performance of such materials with regard to their corrosion and wear resistance however few studies have been conducted which seek to quantify the important phenomena of tribo-corrosive synergy. For example, most of the studies in the field of tribo-corrosion in the past 10 years focus on only a limited number of solutions such as Ringer's Solution[4-5] as well as Oils (Biological and Synthetic) [6], $\mathrm{NaCl}$ [7], Bovine Serum[7] and $\mathrm{H}_{2} \mathrm{SO}_{4}$ [8] and water[9] which all tend to have applications in either prosthesis or industry. Until now, there have been no tribo-corrosion synergy studies which seek to document the effect of common liquid consumables such as milk and orange juice. Such solutions in combination with hard particles from foodstuffs during consumption could give rise to significant tribo-corrosive synergy and may significantly reduce the life expectancy of dental components. The importance of wear synergy in these systems cannot be underestimated and may give rise to significantly higher wear rates. Additionally the effect of tooth brushing and involuntary teeth grinding (bruxism) can also lead to significant wear of teeth and dental materials.

The aim of this paper is to investigate the effect of some common drinks on the tribocorrosive performance of $316 \mathrm{~L}$ Stainless Steel. This is a complex set of test conditions as not only will the $\mathrm{pH}$ be varying between solutions but the viscosity will also be varying. The importance of these variables will be explored throughout this paper. Additionally in response to the recent drive to create maps of tribo-corrosive wear [9-10] this paper will also set out to create a series of maps.

\section{Experimental Details}

Micro-abrasion tests were carried out using the commercially available TE-66 microabrasion tester (Plint and partners Phoenix, UK). The rig consists of a $25 \mathrm{~mm}$ UHMWPE ball which is located between two co-axial shafts. Each shaft is carried in a support bearing. One shaft is driven by a variable speed DC motor whilst the other shaft is connected to a peristaltic pump which is used to provide a slurry feed to the surface- 
counterface contact. A batch counter is connected to the motor to measure and control the number of shaft revolutions.

In this apparatus the test sample is clamped onto a platform which is attached to a pivoted L-shaped arm. The arm is rotated about its pivot until the sample just comes into contact with the ball and no more. This can be achieved by moving a counterweight on the other end of the L-shaped arm.

Loads can be applied to the arm by means of dead weights which are hung on a weight stack at the extreme end of the arm. The arm which holds the sample is not limited to rotating about an axis but can also moved horizontally along the same axis of rotation. By moving the arm in such a way it was possible to perform several different tests on the same sample.

Table 1 Specifications of the micro-abrasion apparatus

\begin{tabular}{|l|l|}
\hline Name and model & Micro-abrasion tester, TE-66 \\
\hline Supplier & Phoenix tribology (Plint),UK \\
\hline Load range & $0.05-5 \mathrm{~N}$ \\
\hline Ball diameter & $25.4 \mathrm{~mm}$ \\
\hline Ball speed range & $30-150 \mathrm{rpm}$ \\
\hline Pump feed rate & Up to $60 \mathrm{ml} \mathrm{h}^{-1}$ (based on $0.5 \mathrm{~mm}$ bore) \\
\hline
\end{tabular}

In all experiments the abrasive particles were Alumina with an average size of 9 microns. The Alumina was supplied by Logitech UK. These particles were mixed with various solutions to produce an abrasive slurry. The complete list of solutions tested can be found in table 1 . To prevent the particles from flocculating it was necessary to constantly agitate them. This was achieved by using a laboratory magnetic stirrer. The slurry was stored in a reservoir and delivered to the contact via a peristaltic pump as stated previously. In all experiments the slurry concentration of $30 \mathrm{~g} / \mathrm{l}$ was fed to a position directly above the wear contact.

UHMWPE was used as the ball material as this provided an inert surface against which corrosion of the counterface could be measured during the micro-abrasion tests. Prior to testing all samples were ground and polished using $1200 \mathrm{Grit} \mathrm{SiC}$ paper. Following the tests, each sample was examined by means of a profile projector and optical microscopy.

The measured wear scars were then used to calculate the removed volume using the standard technique for wear scars of spherical geometry. This technique assumes that the wear scar is perfectly spherical and therefore relies on a perfectly circular worn area. It is recognised that in some tests the worn geometry is not perfectly circular and this may lead to slight errors in the calculated wear volumes. The wear volume $\mathrm{V}$ by a standard technique [12] with the following formula:

$V=\frac{\pi b^{4}}{64 R}$ for $\mathrm{b}<<\mathrm{R}$ 
where $b$ is the wear scar diameter and $\mathrm{R}$ the UHMWPE ball diameter. In all test scenarios two separate experiments were conducted for the same loading conditions to reduce the associated errors.

Corrosion rates were estimated using a Gill AC electrochemical interface (ACM instruments, UK). In this set up the test sample is connected to the working electrode, a reference electrode is connected via capillary tube which allows electrolyte to flow from the contact interface to the reference electrode. A Platinum- Titanium wire mesh connected the corrosion circuit to the auxiliary electrode.

The samples were electrically insulated from the surrounding environment by means of non-conductive tape at all points except a constant exposed area at the point of interaction between the ball and the sample. The sample holder apparatus was composed of nonconductive polymer.

During corrosion tests all samples were held for an initial stabilisation period of 30 seconds at $-1 \mathrm{~V}$ (Saturated Calomel Electrode). Polarisation curves during simultaneous micro-abrasion- corrosion were measured from -1 to $+0.5 \mathrm{~V}$ at a sweep rate of $3.125 \mathrm{mV}$ $\mathrm{s}^{-1}$.

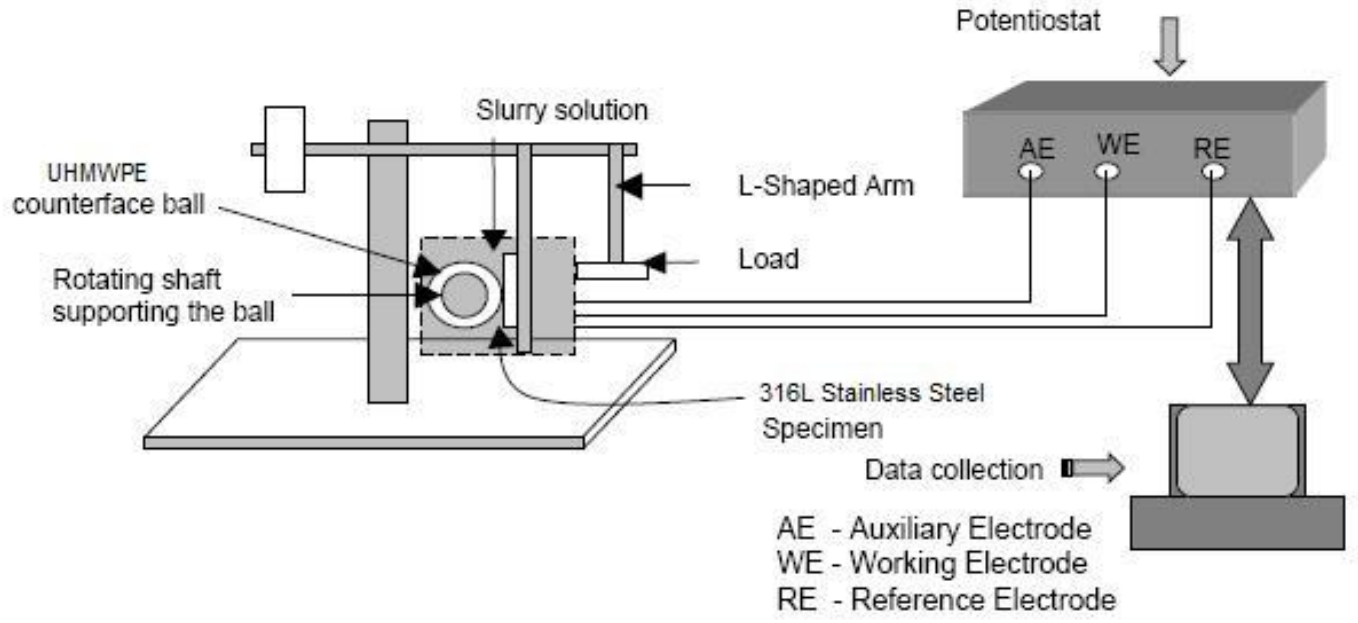

Figure 1 Experimental Apparatus

It is desirable to carry out such tests under de-aerated conditions however this was not possible due to a lack of equipment. It is important to understand however that in such electrochemical experiments a constant background cathodic current due to oxygen reduction will always be present at potentials less than Ecorr (equilibrium potential). In corrosion experiments which have been conducted in non- de-aerated atmospheres it is necessary to compensate for the presence of oxygen reduction currents to obtain accurate corrosion measurements.

Unfortunately in scenarios where the measured anodic current is comparable in magnitude to the background oxygen reduction current, the measured true current is 
small enough to be very sensitive to experimental errors. In this study, the uncorrected data has been reported for the polarization and weight change data to reduce error sensitivity in the micro-abrasion-corrosion maps.

Full experimental details can be found in table 2 .

\section{Table 2}

\begin{tabular}{|l|l|}
\hline Test Sample Material & 316 L Austenitic Stainless Steel (C-0.016, \\
& Si-0.49, Mn- $1.39, \mathrm{P}-0.031, \mathrm{~S}-0.001, \mathrm{Cr}-$ \\
& $16.94, \mathrm{Ni}-10.13, \mathrm{Mo}-2.07, \mathrm{Nb}-0.036, \mathrm{Cu}-$ \\
& $0.39, \mathrm{Co}-0.24, \mathrm{~N}-0.04)$ (Avesta Works, \\
& Sweden) \\
\hline Ball Material & UHMWPE (K-mac Plastics, Michigan \\
& USA) \\
\hline Rotational Speed & $150 \mathrm{rpm}$ \\
\hline Load & $1-5 \mathrm{~N}$ \\
\hline Sliding Distance & $94.25 \mathrm{~m}(1200$ revs) \\
\hline Test Solutions & Leading brand cola, orange juice, milk and \\
& soda. \\
\hline Slurry composition & Test solution mixed with $9 \mu \mathrm{m}$ alpha \\
& Alumina $\left(\mathrm{Al}_{2} \mathrm{O}_{3}\right)$ particles (concentration \\
& $\left.0.03 \mathrm{gcm}^{-3}\right)$ \\
\hline
\end{tabular}

\section{Materials}

The stainless steel samples were supplied by Avesta Works. The stainless steel brand name was Outo Kumpu. During production the steel was hot rolled and finished using treatment 1D (Mill Edge). Additionally the steel was annealed by heating to $1100^{\circ} \mathrm{C}$ and then quenched using forced air and water.

Hardness tests on the unworn and wear scar surfaces revealed that there was a reduction in material hardness. This is likely due to a thin layer of work hardened material on the surface of the steel due to the production processes previously mentioned.

Table 3

\begin{tabular}{|l|l|}
\hline 316 L Stainless Steel Hardness Values \\
\hline Sample surface before testing & $251.5 \mathrm{Hv}$ \\
\hline Wear Scar Surface after testing & $202.5 \mathrm{Hv}$ \\
\hline
\end{tabular}

The density of this steel was $7990 \mathrm{~kg} / \mathrm{m}^{3}$. The UHMWPE ball was manufactured by injection moulding and supplied by K-Mac Plastics. The ball hardness was 500Hv. 


\section{Results}

\section{Polarisation Curves}

Figure 2(a) shows the polarisation curves obtained for the various beaker experiments. Passive behaviour can clearly be seen on the milk and soda curves and both cola and orange show pre passivation phenomena. Anodic current densities are also considerably lower for all solutions tested in the beaker experiments than in the abrasion-corrosion experiments (figures 2(b)-(e)) which indicates that passivation is taking place.

Figures $2(\mathrm{~b}-\mathrm{e})$ shows the polarization curves obtained for the corrosive slurry experiments. It can be seen in all slurry tests the abrasive action of the alumina particles prevents any meaningful passivation from occurring and the anodic currents tend to remain in the active regime.

In figures 2 (b), (c) and (e) (coke orange and soda), there is a trend of increasing corrosion current with increasing applied load from loads $1-4 \mathrm{~N}$. At $5 \mathrm{~N}$, there is a decrease in corrosion current which is most likely due to the formation of passive films. It should also be noted that there is a much smaller change in corrosion current between $2 \mathrm{~N}$ and $4 \mathrm{~N}$ than $1 \mathrm{~N}$ and $2 \mathrm{~N}$. Figure 3 shows this more clearly.

For the milk slurry figure 2(d) the situation is a little more complex. The $1 \mathrm{~N}$ and $2 \mathrm{~N}$ curves show a much higher corrosion current than the other loads however, this was thought to be due to an experimental error when inputting the corrosion area into the ACM polarisation tester.) Using the different area for loads $1 \mathrm{~N}$ and $2 \mathrm{~N}$, input into the tester to calculate the corrosion current, it is found that there is an obvious minima in the corrosion current density at intermediate loads. It is also important to note that the corrosion potential for $5 \mathrm{~N}$ was noticeably higher in milk than the other loads tested. This result appeared in both attempts at this experiment. It is accepted that the crude correction for the $1 \mathrm{~N}$ and $2 \mathrm{~N}$ corrosion potentials will have accuracy issues. 


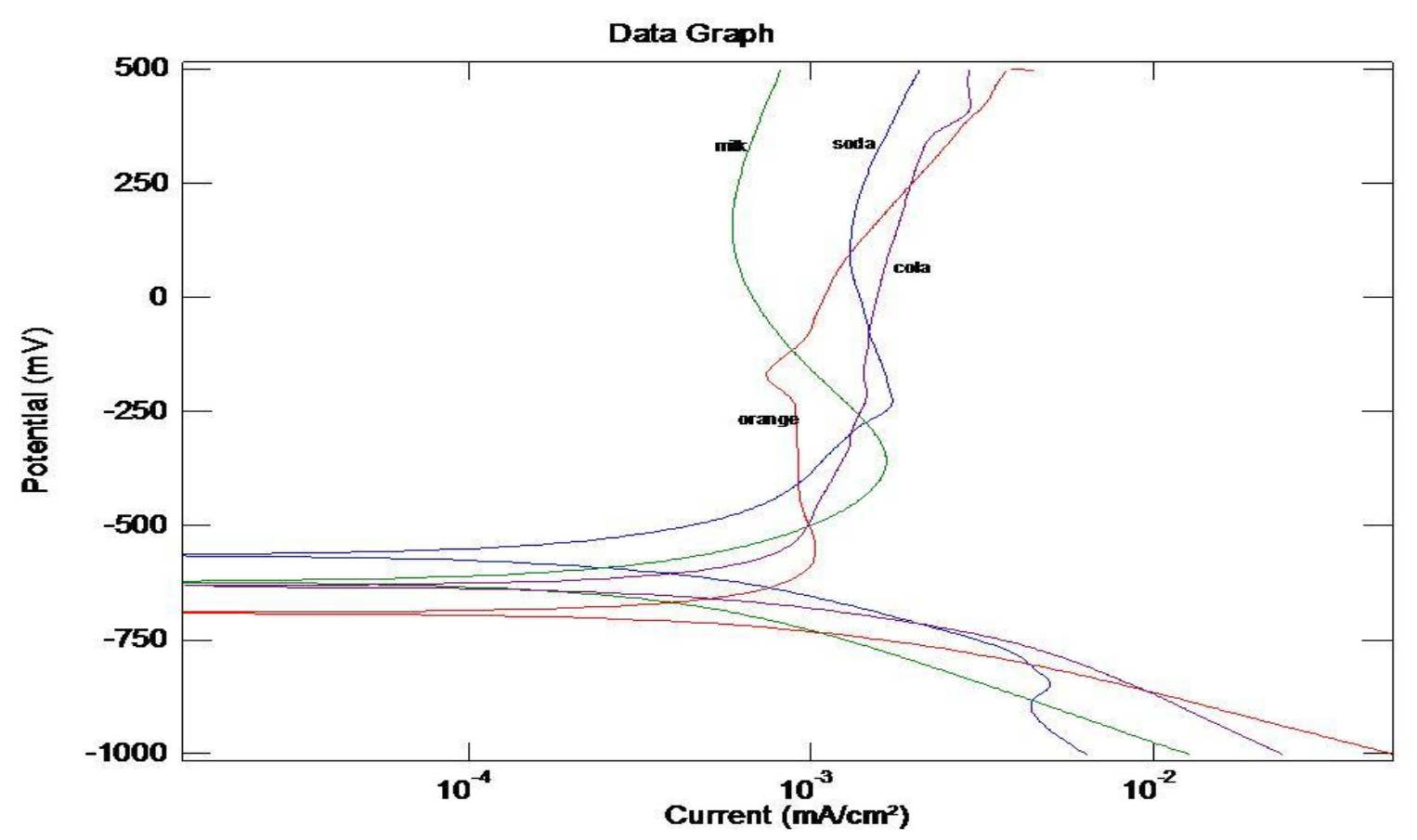

Figure 2(a) Corrosion Only Beaker Experiment

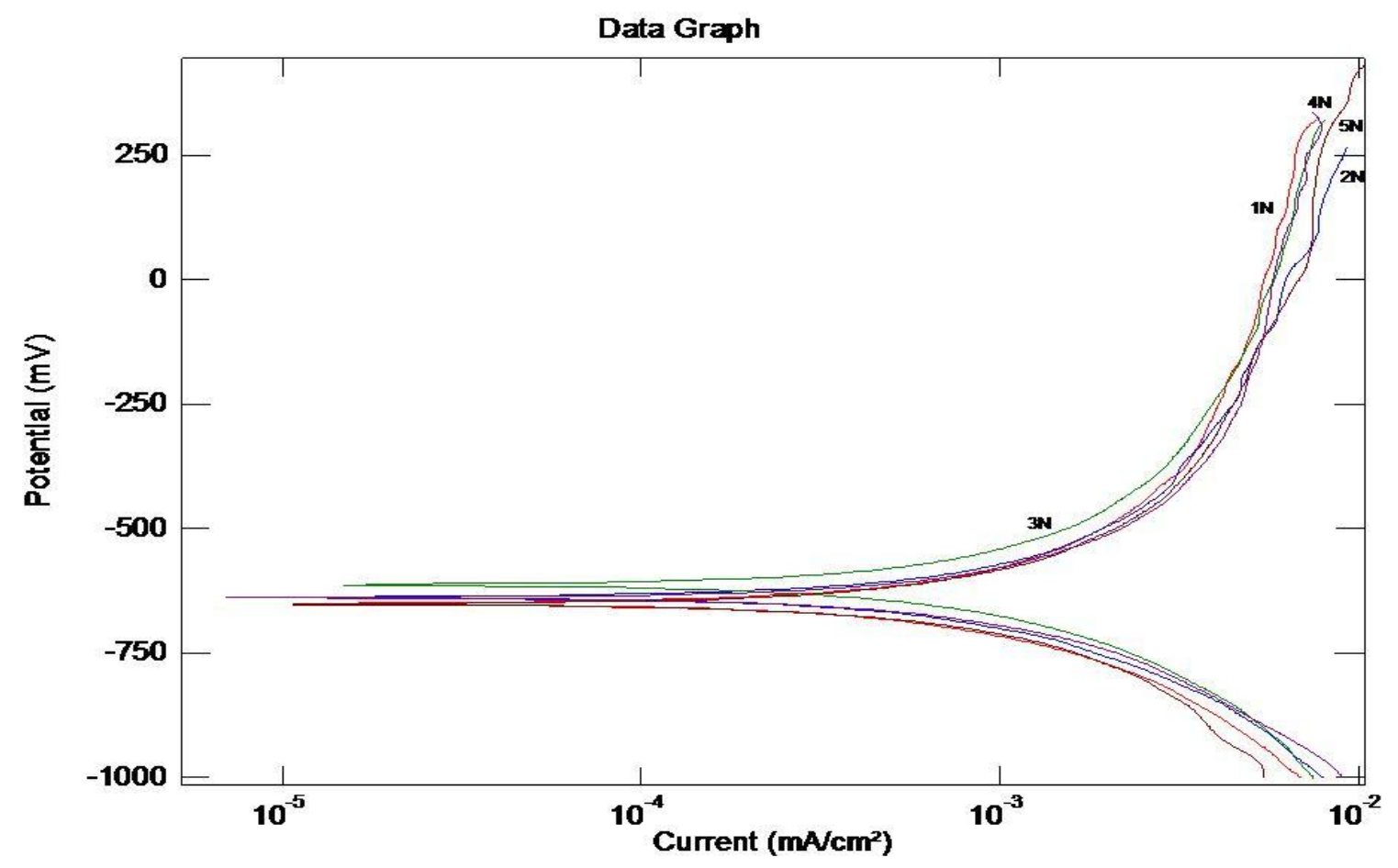

Figure 2(b) Polarization curves for abrasive cola slurry 


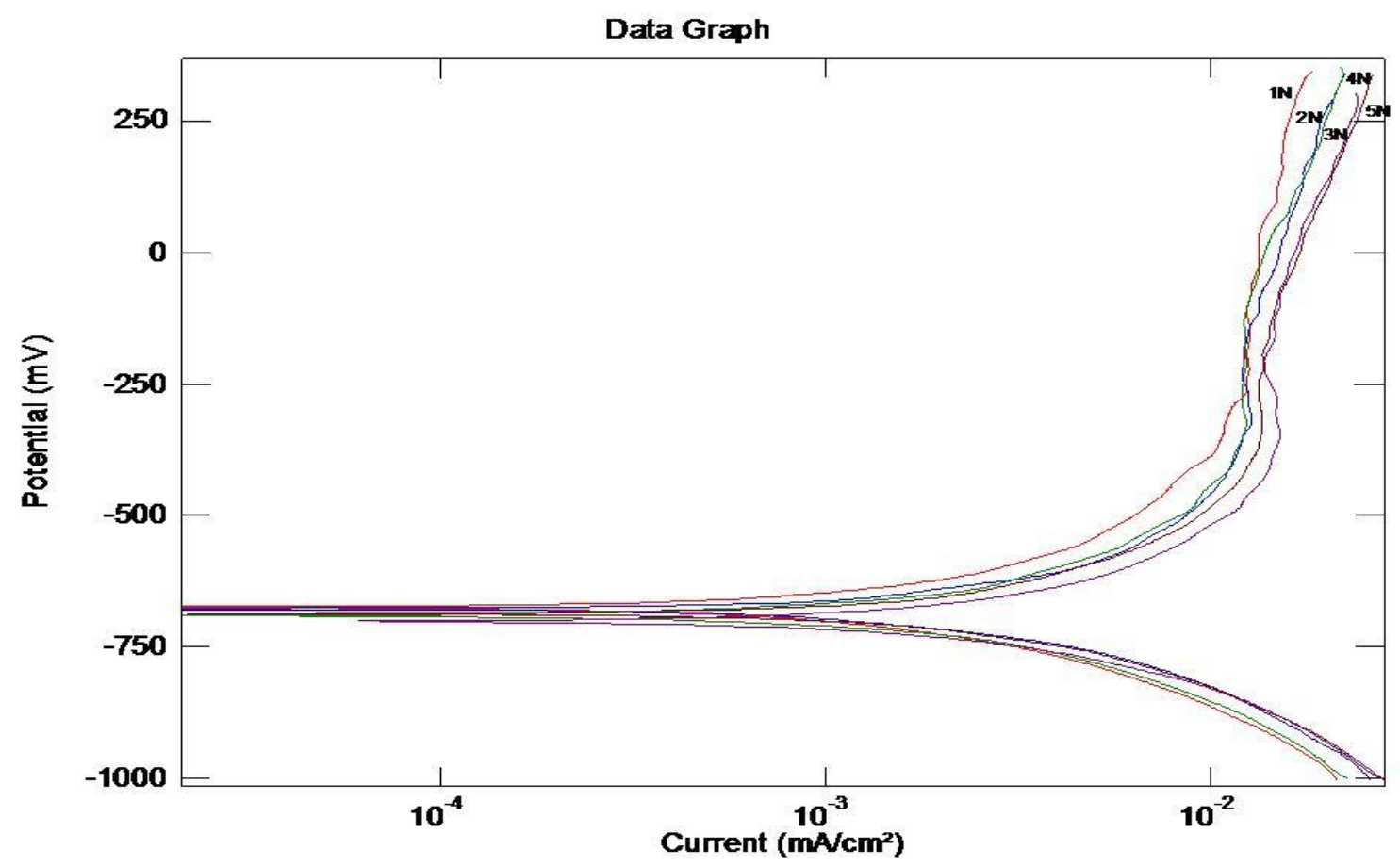

Figure 2(c) Polarization curves for abrasive orange slurry

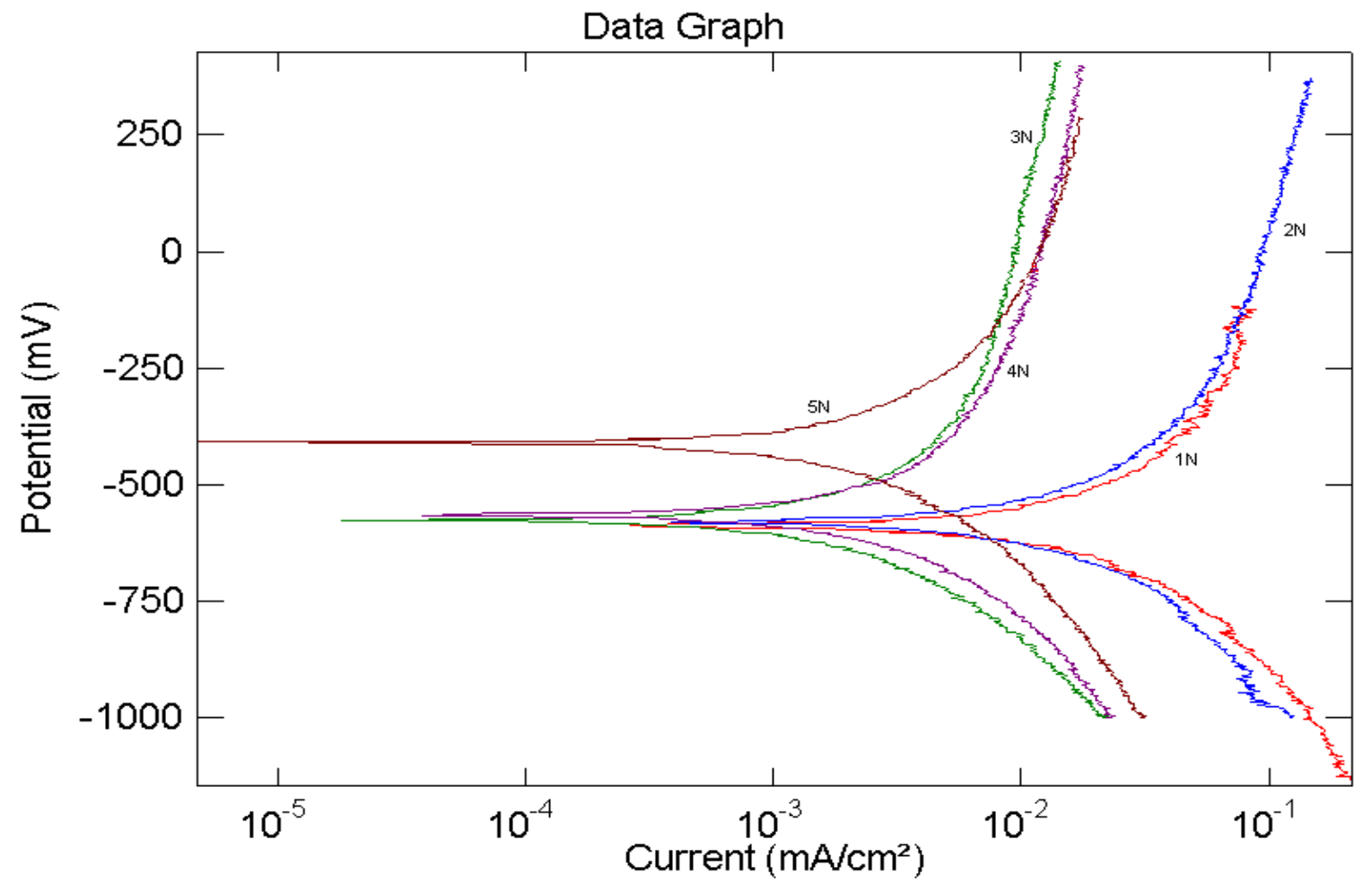

Figure 2(d) Polarisation curves for abrasive milk slurry 


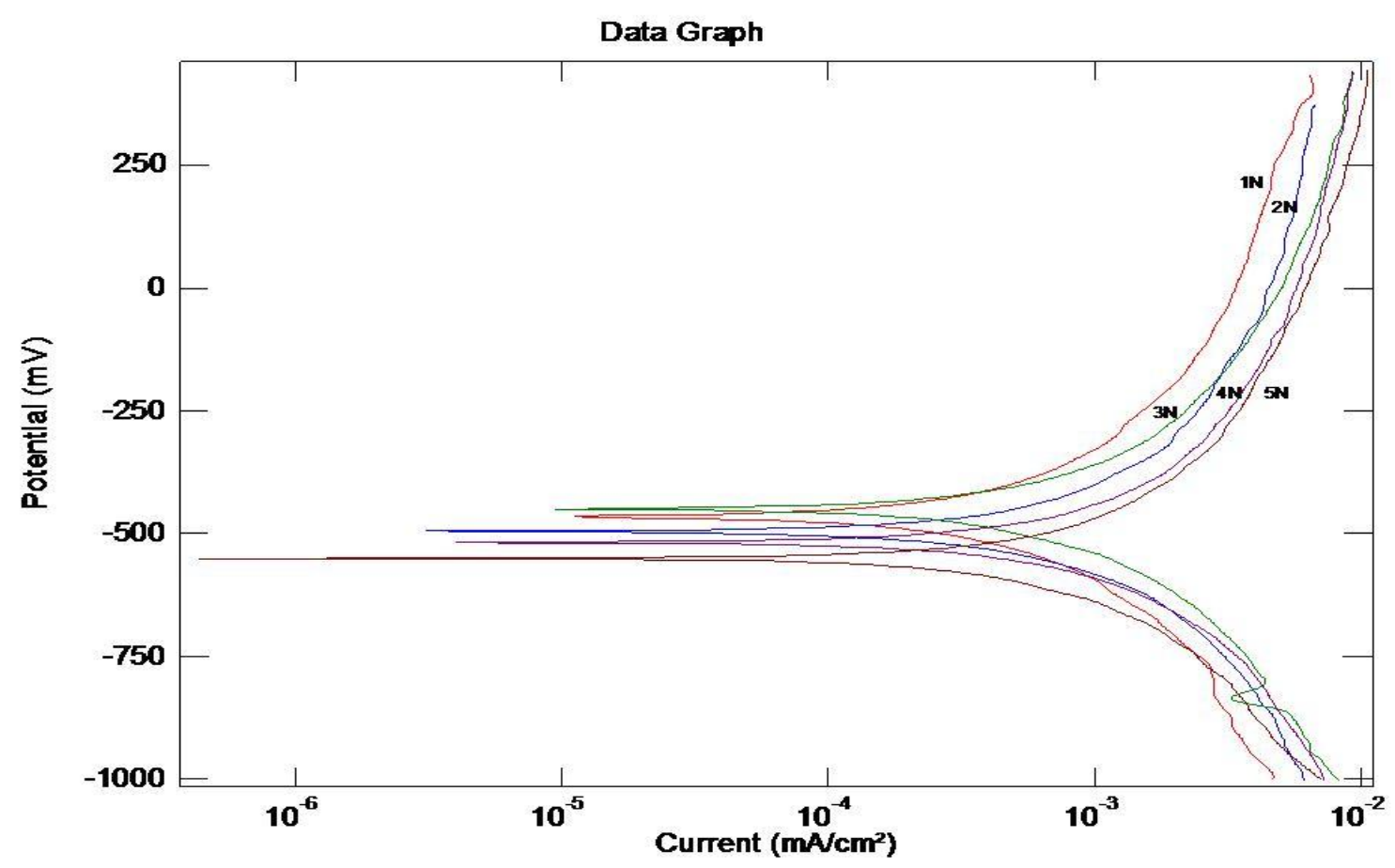

Figure 2(e) Polarisation curves for abrasive soda slurry

\section{Weight Change Data}

The resulting wear scars and corrosive currents were analysed using the wear-corrosion analysis developed by Yue and Shi [13]. In this anaylsis

$\mathrm{K}_{\mathrm{ac}}=\mathrm{K}_{\mathrm{a}}+\mathrm{K}_{\mathrm{c}}$

Where $\mathrm{K}_{\mathrm{ac}}$, is the total micro-abrasion-corrosion weight loss, $\mathrm{K}_{\mathrm{a}}$ is the total micro-abrasion weight loss and $\mathrm{K}_{\mathrm{c}}$ is the total corrosive weight loss. It is important to understand that the phenomenon of wear-corrosion synergy requires the expansion of the terms $\mathrm{K}_{\mathrm{a}}$ and $\mathrm{K}_{\mathrm{c}}$ as:

$\mathrm{K}_{\mathrm{a}}=\mathrm{K}_{\mathrm{ao}}+\Delta \mathrm{K}_{\mathrm{a}}$

where $\mathrm{K}_{\mathrm{ao}}$ is the pure micro-abrasion weight loss in the absence of corrosion and $\Delta \mathrm{K}_{\mathrm{a}}$ is the synergistic effect of corrosion on the micro-abrasion.

$\mathrm{K}_{\mathrm{c}}$ is expanded as:

$\mathrm{K}_{\mathrm{c}}=\mathrm{K}_{\mathrm{co}}+\Delta \mathrm{K}_{\mathrm{c}}$

where $\mathrm{K}_{\mathrm{co}}$ is the pure corrosion weight loss in the absence of abrasion and $\Delta \mathrm{K}_{\mathrm{c}}$ is the additive effect of micro-abrasion on the corrosive weight loss. 
Collecting the terms in 3 and 4 and utilising equation 2, the total micro-abrasioncorrosion weight loss is defined as:

$\mathrm{K}_{\mathrm{ac}}=\mathrm{K}_{\mathrm{ao}}+\Delta \mathrm{K}_{\mathrm{a}}+\mathrm{K}_{\mathrm{co}}+\Delta \mathrm{K}_{\mathrm{c}}$

The term $\mathrm{K}_{\mathrm{ac}}$ was found from the resulting wear scars of the wear corrosion experiments. The corrosion rate data from the same experiment were derived using Faraday's Law as:

$\mathrm{K}_{\mathrm{c}}=\mathrm{MIt} / \mathrm{ZF}$

where $\mathrm{K}_{\mathrm{c}}$ is the corrosion rate, $\mathrm{M}$ is the atomic mass of the material, $\mathrm{I}$ is the measured corrosion current, $\mathrm{t}$ is the exposure time, $\mathrm{Z}$ is the number of valence electrons involved the corrosion of the steel and F is Faraday's constant $\left(96500 \mathrm{C} \mathrm{mol}^{-1}\right)$.

$\mathrm{K}_{\mathrm{ao}}$ was obtained by carrying out pure abrasion experiments with offset potentials which ensure that corrosion is only taking place in the cathodic regime.

These potentials were estimated using polarization curves obtained for the abrasioncorrosion experiments. Unlike most studies which tend to use a constant offset potential such as $-1 \mathrm{~V}$ for all pure abrasion experiments a series of offset potentials were used here with the aim of a near constant cathodic current density. Akonko et al discovered that the selected offset potential had a significant effect on the degree of hydrogen embrittlement and that the resulting wear varied by up to 1 order of magnitude depending on the selected cathodic protection potential [14]. It can be hypothesised that the degree of embrittlement is related to the number of reduced hydrogen ions which itself is related to the resulting catholic current (It is recognised that there will be other cathodic reduction reactions). Therefore in order to ensure that the same degree of hydrogen embrittlement occurs on all wear samples, the cathodic current and not the cathodic potential is the most important factor here. Plotting all of the polarization curves from the abrasion-corrosion experiments together makes it possible to determine a common current in the cathodic regime for all of the tested loads and solutions. This was determined to be $7 \times 10^{-3}$ $\mathrm{mA} / \mathrm{cm}^{2}$. This current was then used to select the required offset potential for each of the individual experimental conditions to calculate $\mathrm{K}_{\mathrm{a} o}$. The range of these offset potentials varies from $-600 \mathrm{mV}$ to $-900 \mathrm{mV}$. This method has the advantage over selecting a constant offset potential in that a constant offset potential tends to lead to a varying offset current for varied experimental conditions and as a result the degree of hydrogen embrittlement also varies between loads and solutions etc.

$\mathrm{K}_{\mathrm{co}}$ was estimated by placing the corrosive cell (ie sample + working electrode, reference electrode and counter electrode) in a beaker containing the relevant test solution and Silver Chloride powder. The resulting corrosion current of the exposed static surface was then used to calculate the corrosion only rate utilising the Faraday law as explained previously.

All other values can be calculated using equations 2, 3 and 4 . 
During the analysis of the obtained results it became apparent very quickly that the weight losses due to abrasion dwarf the weight losses due to corrosion. This is to be expected of stainless steels which are regularly chosen for their strong corrosion resistant properties. Plotting all weight loss contributions on the same graph - which has become standard procedure in such studies - produces a graph which is interpreted with difficulty and for that reason the results for $\mathrm{Kac} \mathrm{Ka}$ and $\mathrm{Kc}$ have been plotted on separate graphs (figures 3-5).

Both figures 4 and 5 are almost identical due to the almost negligible contribution from corrosion in all conditions tested.

For the corrosion plots (figure 3 ) it can be seen that the soda and cola plots are very similar, with the results for the cola slightly above those for soda which is to be expected due to its lower $\mathrm{pH}$ value. Orange also shows a similar plot to cola and soda which is inclined upwards from left to right. It is important to note that orange is also at a much higher position than the cola and soda plots. The exception to the trends shown for the other solutions is the plot for milk. It is possible however that the milk plot will show similar behaviour if the load range is extended.

For the abrasive plots (figure 5) cola and orange tend to follow the Archard equation of wear [15] which can be written as:

$\mathrm{V}=\mathrm{k}$ S W [16]

$\mathrm{V}$ is the removed volume, $\mathrm{S}$ is the total sliding distance, $\mathrm{W}$ the applied load and $\mathrm{k}$ the specific wear rate.

Soda also follows this equation from $1-4 \mathrm{~N}$ however a sudden drop in wear rate is encountered at $5 \mathrm{~N}$ for soda. It is interesting to note that in the abrasive plots, milk also shows the greatest deviation from the Archard equation and also the plots for the other solutions. 


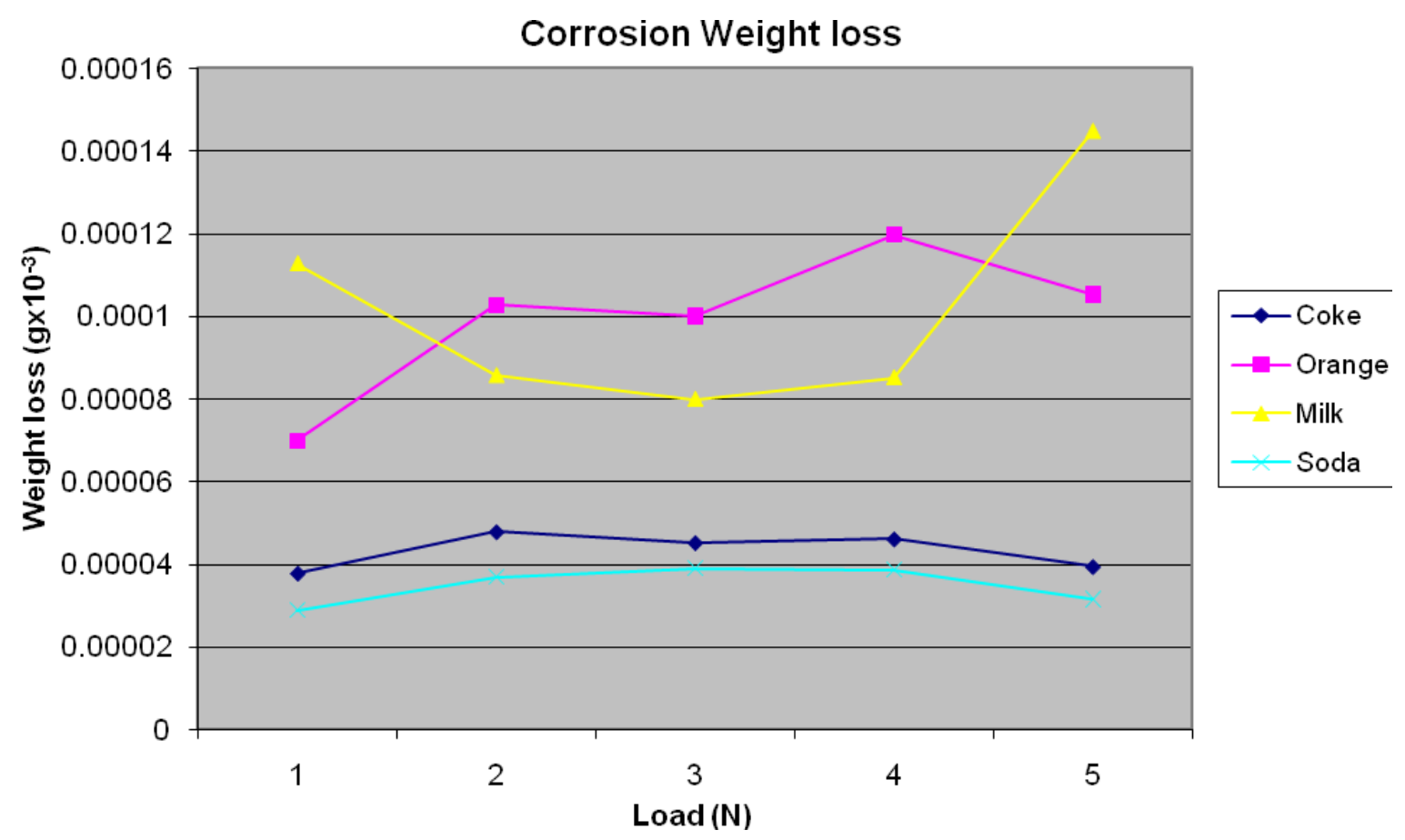

Figure 3 Corrosion Weight Loss (Kc)

\section{Total Microabrasion-corrosion weight loss}

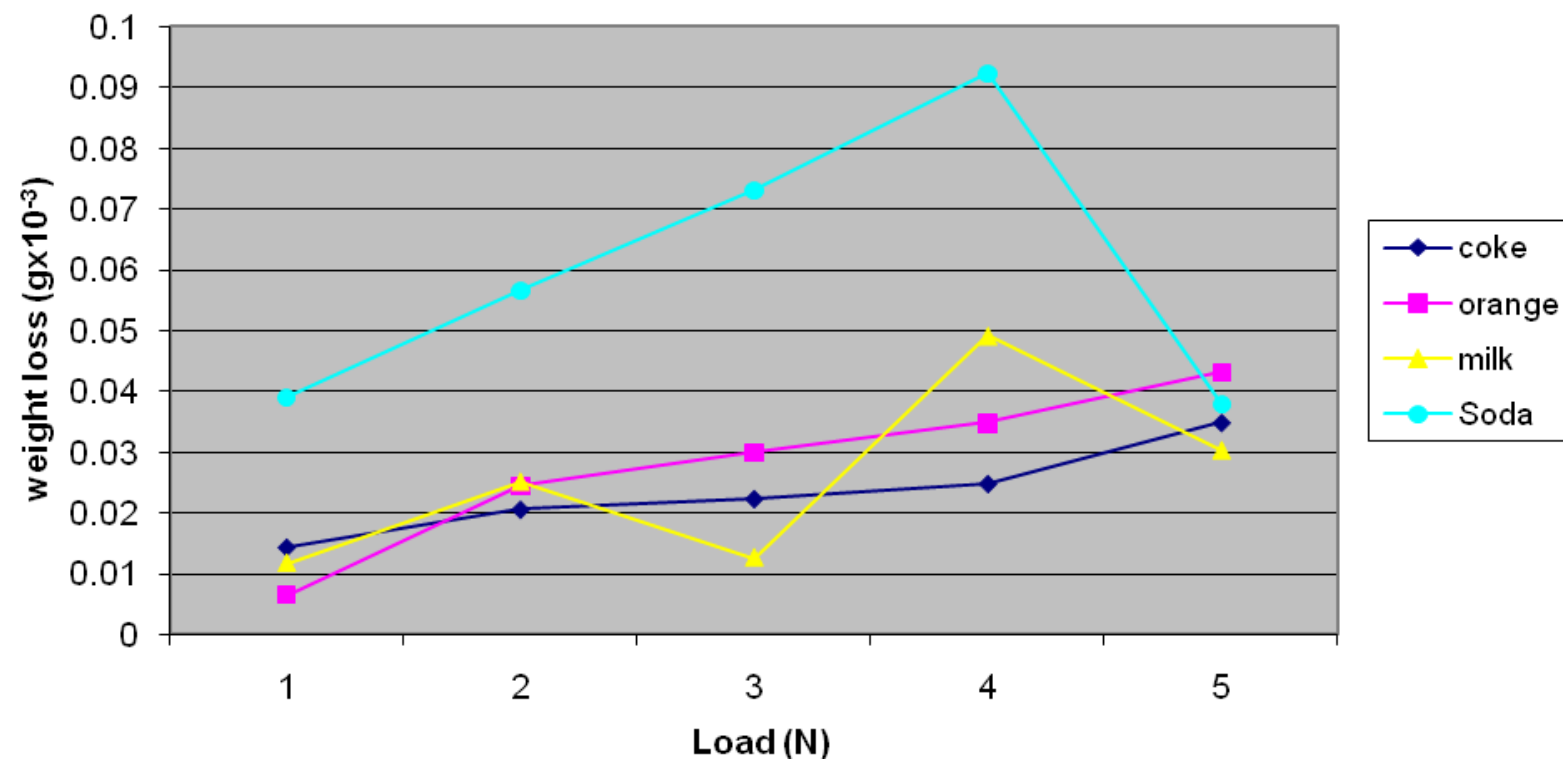

Figure 4 Total weight Loss (Kac) 


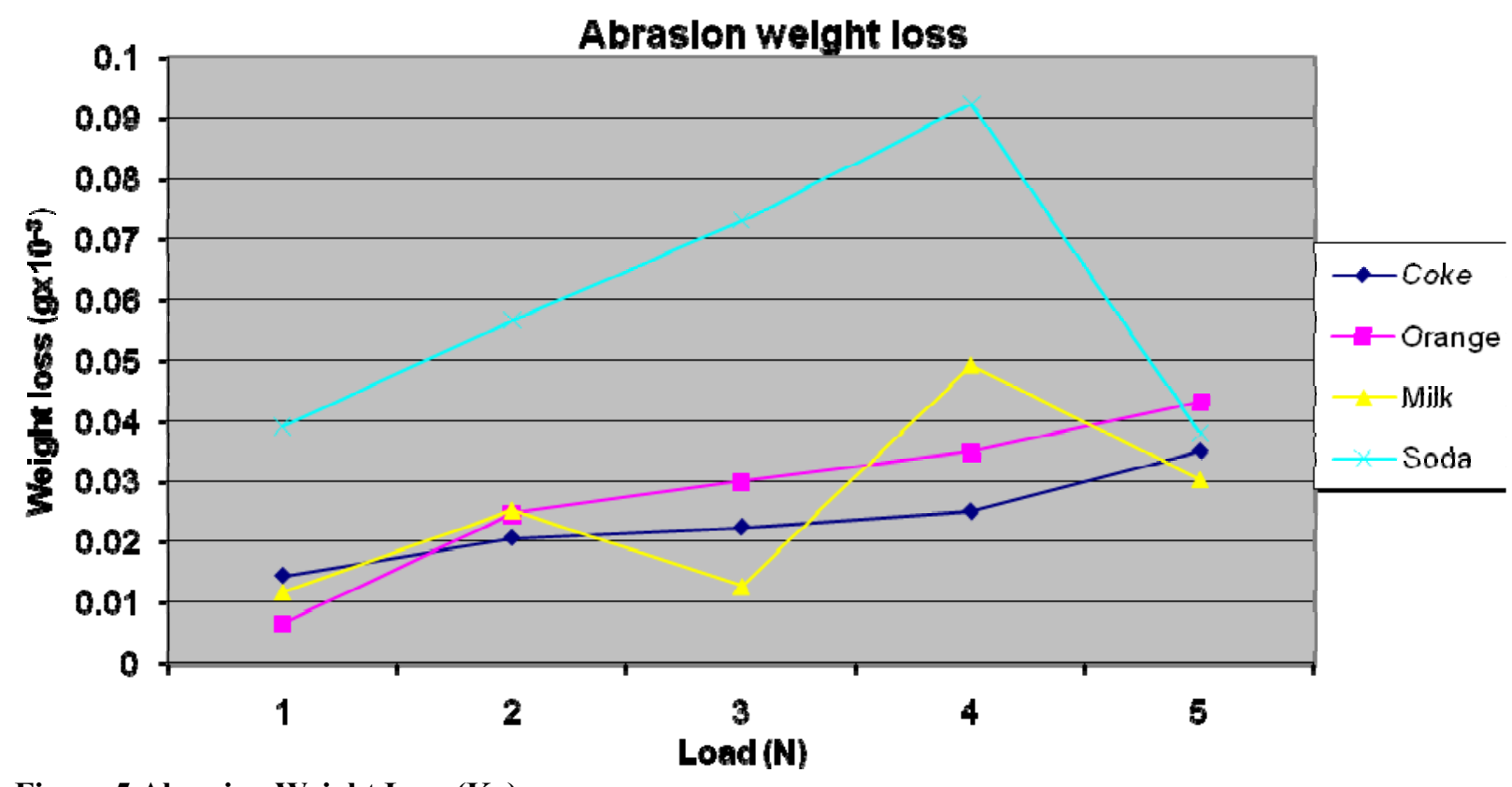

Figure 5 Abrasion Weight Loss (Ka)

All experiments were run twice to identify and minimise errors. A plot of the associated errors for Milk during abrasion-corrosion can be seen in figure 6 .

Milk Kac

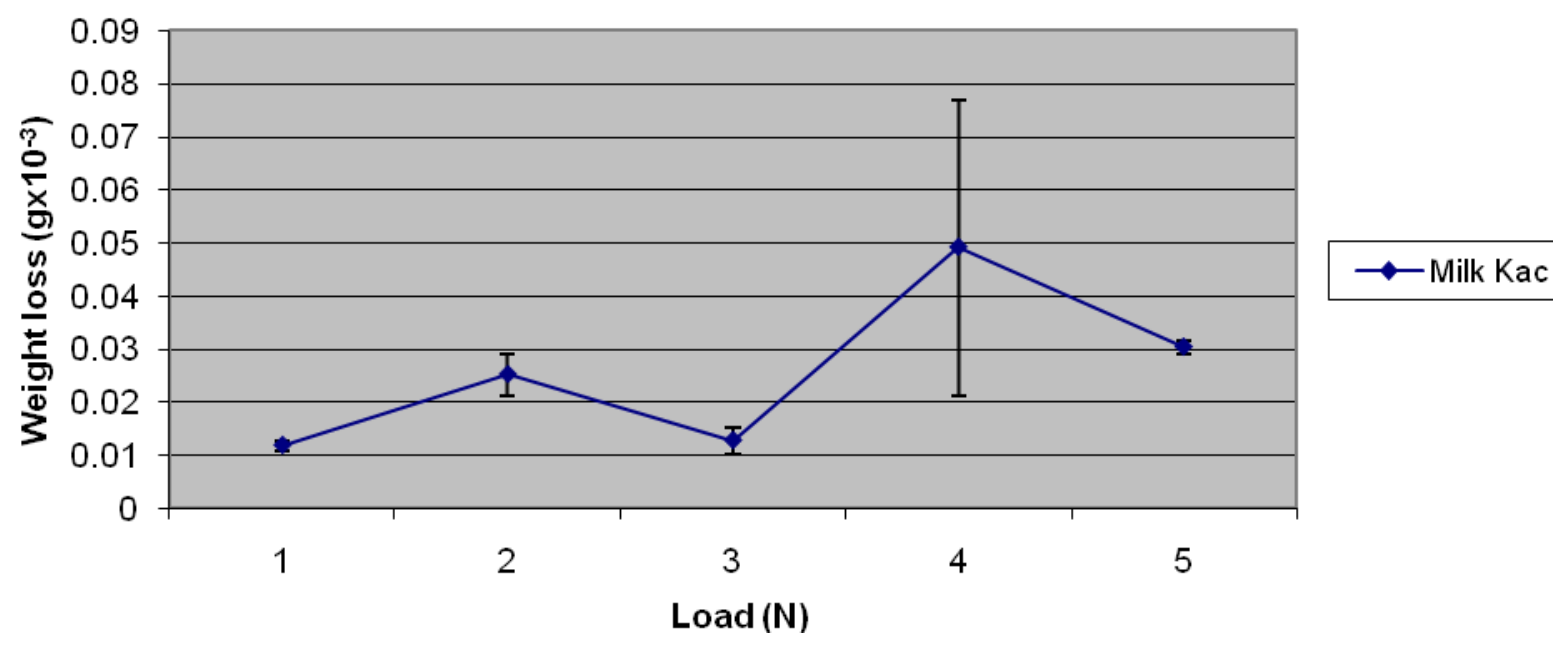

Figure 6 Variation in weight loss Kac for Milk with increasing applied load. Error bars are based on two consecutive readings.

The average $\mathrm{K}_{\mathrm{ac}}$ errors for Cola, Orange, Milk and Soda are $\pm 15.2 \%, \pm 25.7 \%, \pm 20.5 \%$, $\pm 13.6 \%$ respectively. This gives an average experimental error of $\pm 18.75 \%$. The errors associated with corrosion measurements were all smaller than the smallest $\mathrm{K}_{\mathrm{ac}}$ error. 


\section{Optical Microscopy of Worn Surfaces}

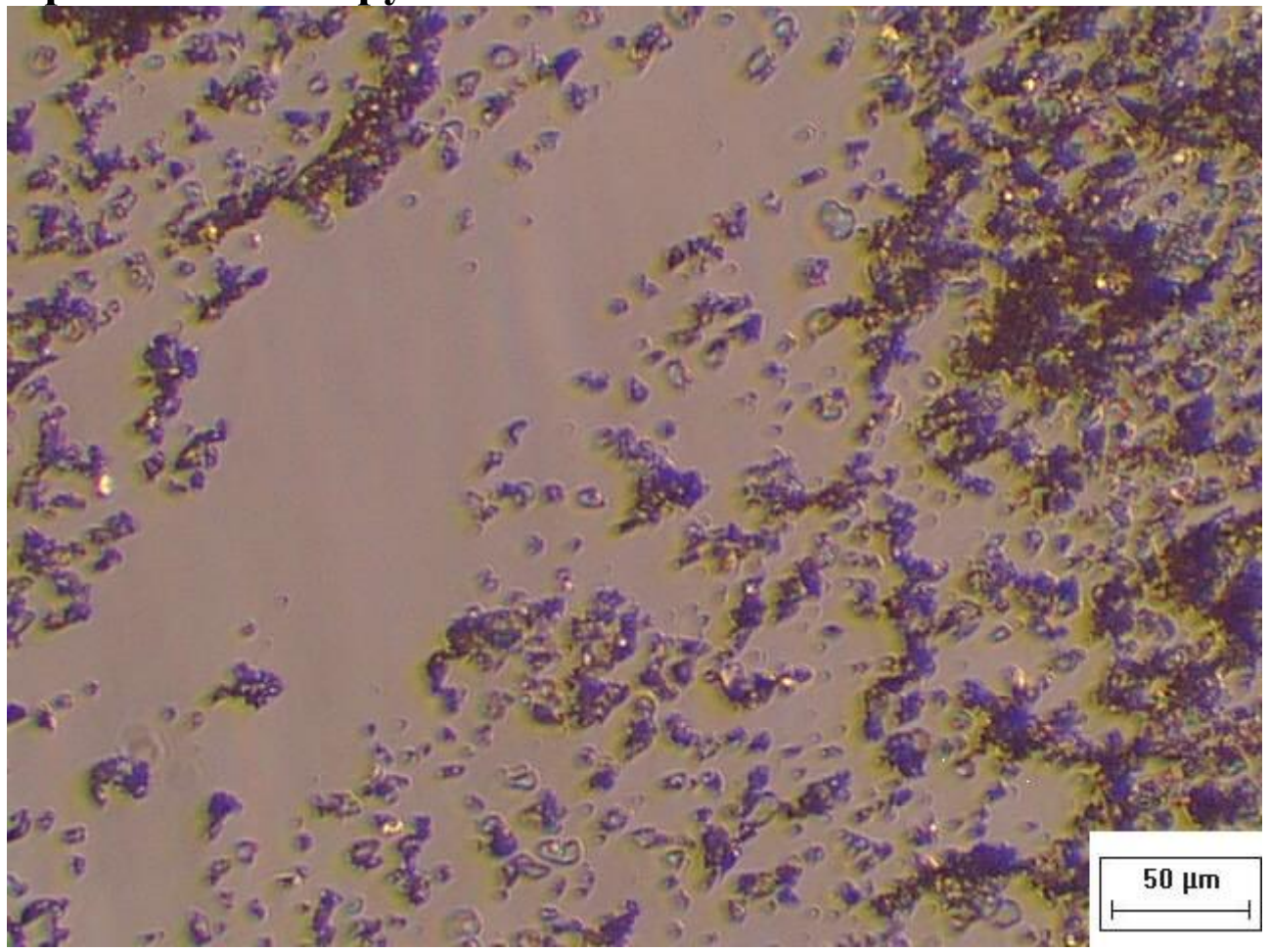

Figure 7(a) Alumina sand under 100* magnification

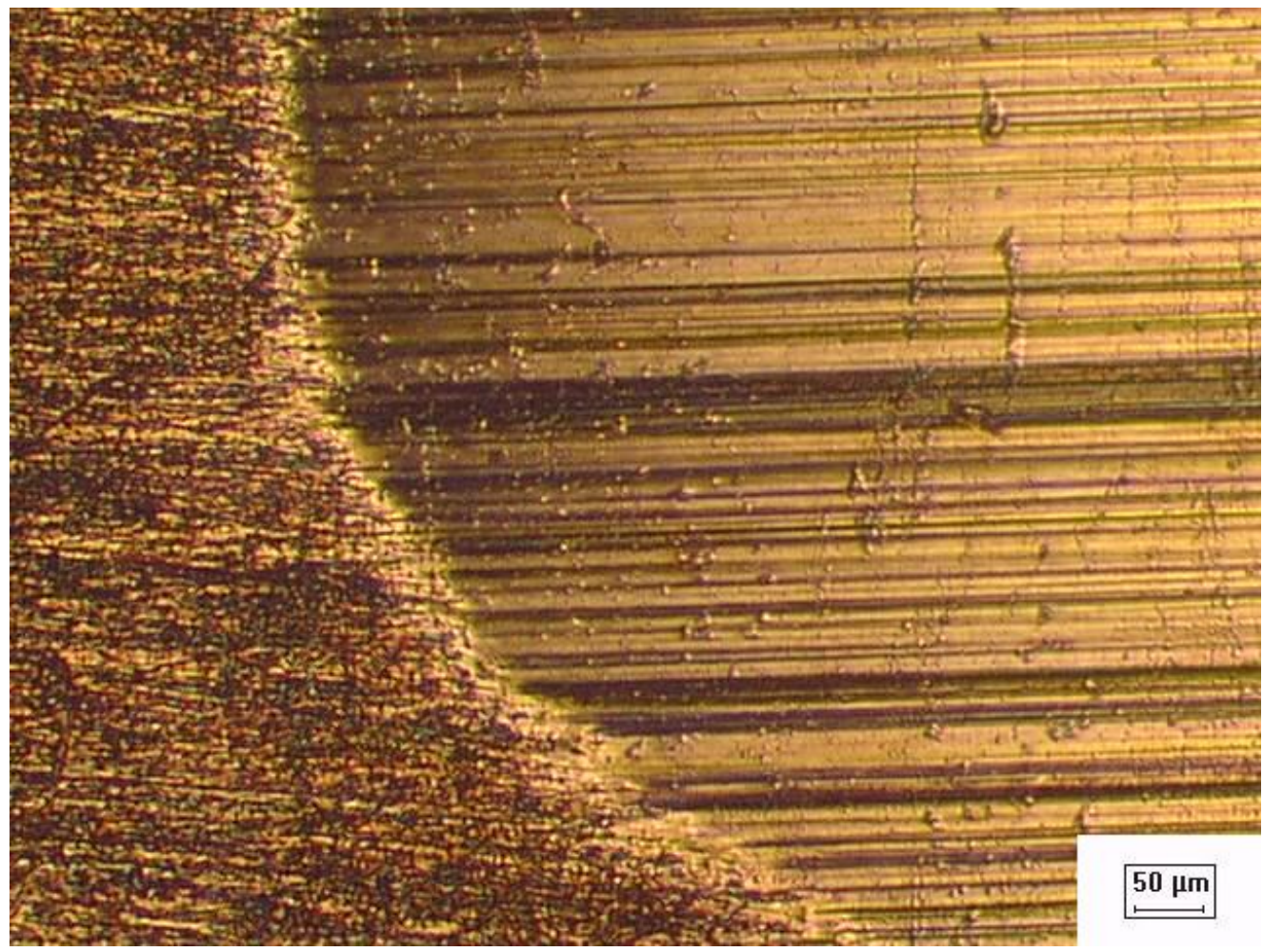

Figure 7(b) Soda 5N after abrasion-corrosion 50* 


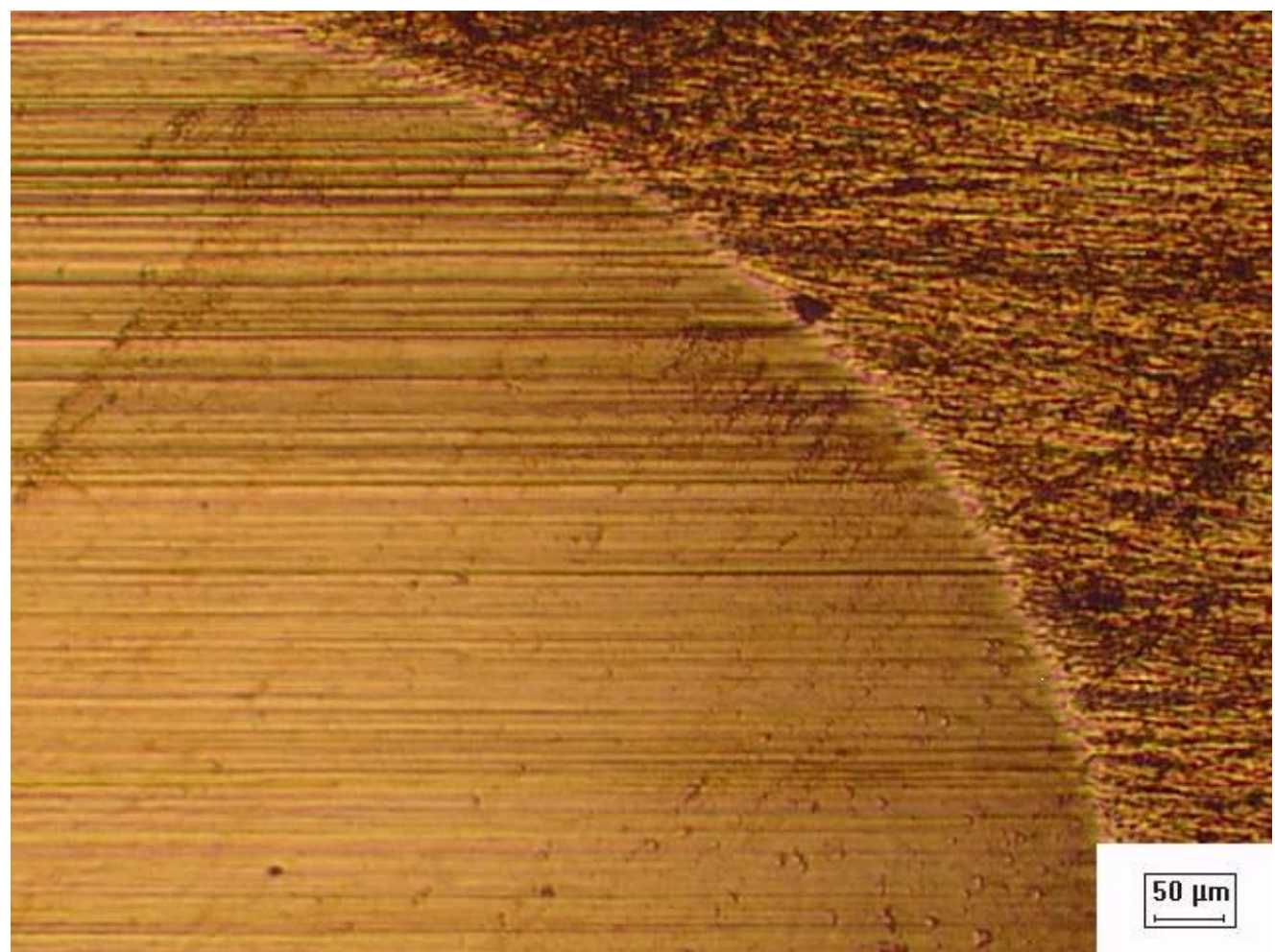

Figure 7(c) Soda 5N Abrasion only 50*

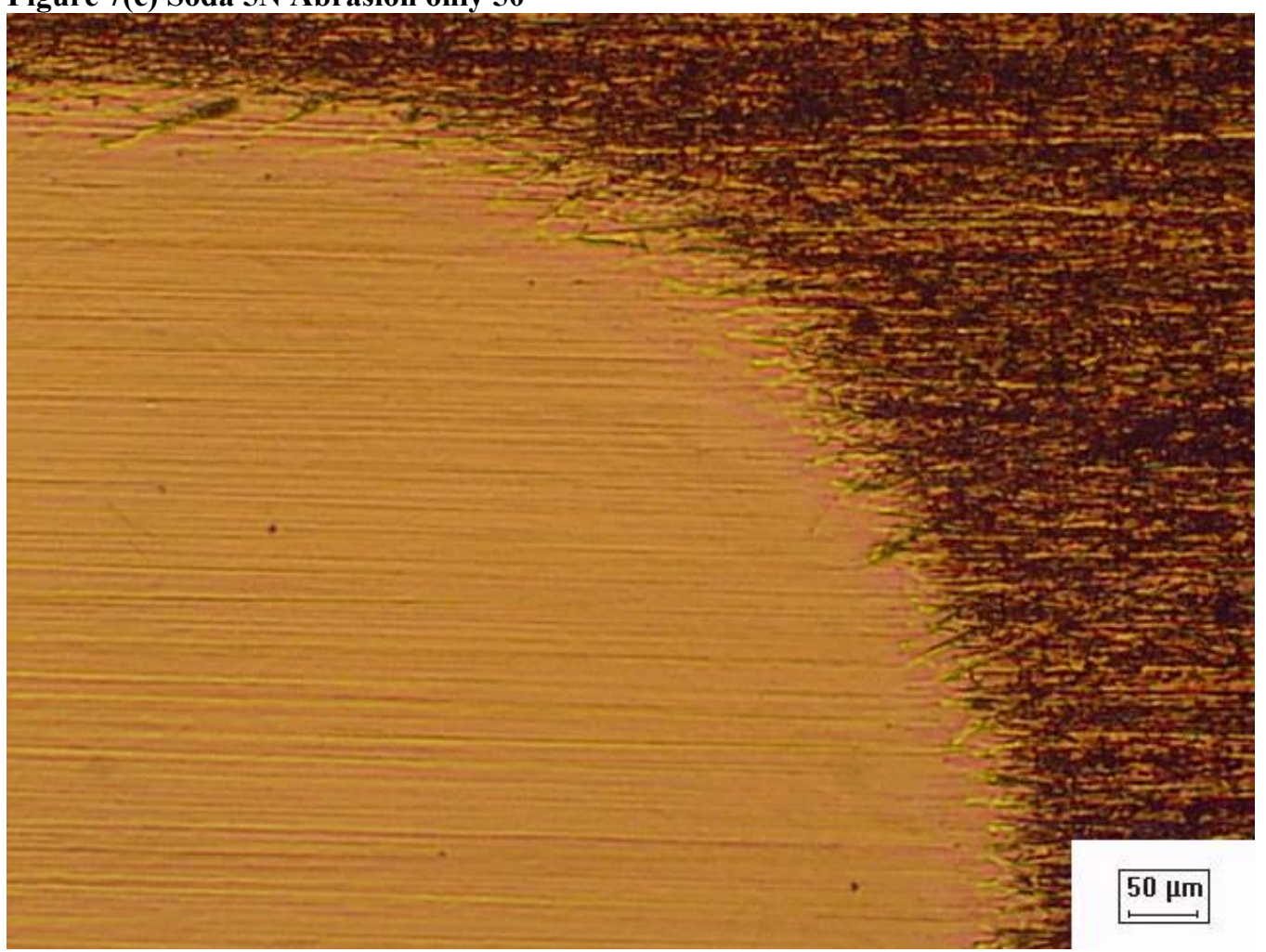

Figure 7(d) Cola 5N after abrasion-corrosion 50* 


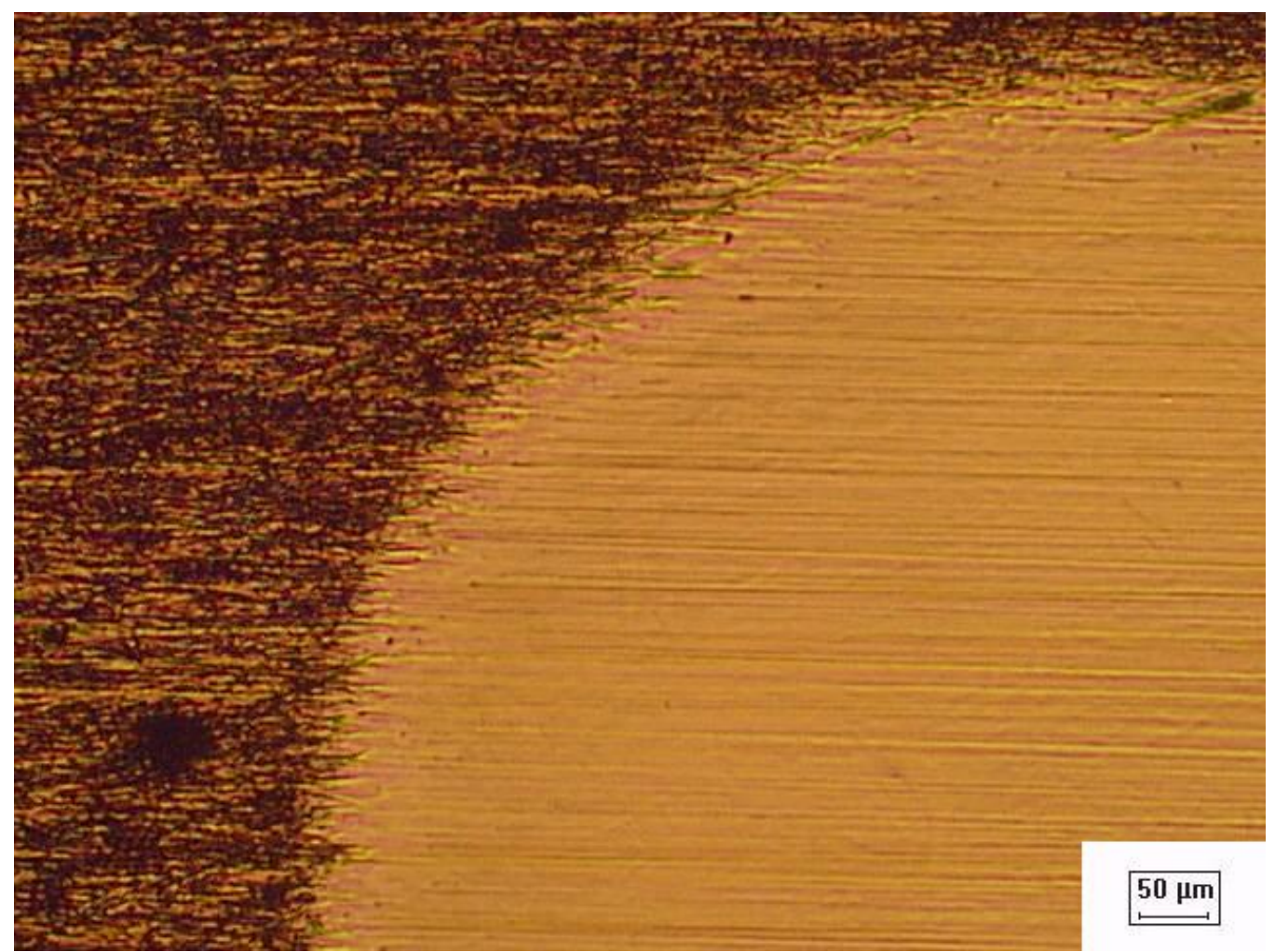

Figure 7(e) Cola 5N abrasion only 50*

Figure 7(a) shows that the Alumina particles are fairly rounded in composition. The particle size is almost constant throughout the sample. Larger particles are shown as a result of flocculating alumina particles.

It can be clearly seen for the Soda -fig 7(b) and Cola - fig 7(d) -surfaces that wear is significantly more severe for the soda experiments.

\section{Discussion}

\section{Polarization Data}

It can be seen that the corrosion current is greatest for cola and lowest for soda in the beaker experiments (figure 2(a)). The trend of increasing corrosion current with decreasing $\mathrm{pH}$ values has been observed previously [17]. However, it should be noted that previous observations identify negligible difference in corrosion rate between $\mathrm{pH} 4$ and 10 . In the beaker experiments conducted here, there is a reduction between corrosion rates for milk ( $\mathrm{pH}$ 6.7) and soda ( $\mathrm{pH}$ 7.8). In the original diagram, there is a reduction in corrosion rate at $\mathrm{pHs}$ above 10 . This is believed to be due to an increase in the reaction of oxygen with $\mathrm{Fe}(\mathrm{OH})_{2}$ (hydrated iron oxide) to form the more protective $\mathrm{Fe}_{2} \mathrm{O}_{3}$. It can be hypothesised that the presence of $\mathrm{CO}_{2}$ bubbles in the soda may cause this change to occur at a lower $\mathrm{pH}$ than in non-gaseous solutions as shown here. 
Using Pourbaix diagrams for Iron, Chromium and Nickel [18], we can predict the active and passive potentials for all of the solutions tested. It should be noted that the potential range tested here does not show clearly the passive regimes for low $\mathrm{pH}$ solutions such as cola and orange which should occur above $0.5 \mathrm{~V}$. It can be seen in figure 2 that there are slight kinks in the curves for cola and orange between 250 and $500 \mathrm{mV}$. These kinks tend to immediately precede passivation behaviour. The reduction in anodic current for orange at a potential range $-600 \mathrm{mV}$ to $-100 \mathrm{mV}$ is not likely to be true passivation and is likely to be a pre-passivation phenomena. For Soda and Milk the kinks occur at $-250 \mathrm{mV}$ and $350 \mathrm{mV}$ respectively. It is interesting to note that in general the passivation potentials tend to follow that which is predicted by the associated Pourbaix diagrams, (ie decreasing passivation potential with increasing $\mathrm{pH}$ ). However, it should be noted that the presence of gas bubbles in the soda and cola has the effect of increasing the passivation potential in high pHs (ie milk passivates before soda) and decreasing the passivation potential in low pHs (ie cola passivates before orange). It is not fully understood why this happens.

The polarisation curves which are obtained for the abrasion - corrosion experiments (figures 2(b-e)) do not show the same increase in corrosion current with decreasing $\mathrm{pH}$. Instead they show a different relationship with a general increase in current with increasing solution viscosity. This is an interesting result. A possible explanation is that the higher viscosity is acting as a lubricant which in turn allows easier movement of contact surfaces which in turn removes more passive film.

\section{Weight loss data}

It is evident from figures 3-5 that there is a complex relationship which determines the resulting weight loss at each load. The important variables which have been identified are the applied load, solution $\mathrm{pH}$ and solution viscosity. The $\mathrm{pHs}$ and solution viscosities are summarised in table 4. $\mathrm{pH}$ measurements were taken using a Hanna instruments HI 8424 digital $\mathrm{pH}$ tester. Rheological experiments were not conducted here and viscosity data was taken from [19-21]

Table 4

\begin{tabular}{|l|l|l|l|l|}
\hline Solution & Cola & Orange & Milk & Soda \\
\hline $\mathrm{pH}$ & 2.2 & 3.5 & 6.7 & 7.8 \\
\hline $\begin{array}{l}\text { Viscosity } \\
(\mathrm{cP})\end{array}$ & 1.8 & $\begin{array}{l}\approx 8 \text { (pulp } \\
\text { concentration } \\
\text { dependant) }\end{array}$ & 2 & 1 \\
\hline
\end{tabular}

Increasing solution viscosity is an important parameter as it acts to reduce surface friction up to certain speeds and viscosities as determined by a Stribeck curve [22]. The reduction in surface friction results from increasing film thickness with increasing viscosity at a constant speed and load. This will also affect the transitions in wear regime as has been 
found by Williams and Hyncica [23] where the transition from 3 body to 2 body wear has been identified as proportional to the ratio $(\mathrm{D} / \mathrm{h})$, where $\mathrm{D}$ is the major axis particle diameter and $\mathrm{h}$ the film thickness. It should be expected that higher viscosity fluids will transition to 2 body wear at higher loads than the lower viscosity fluids tested here.

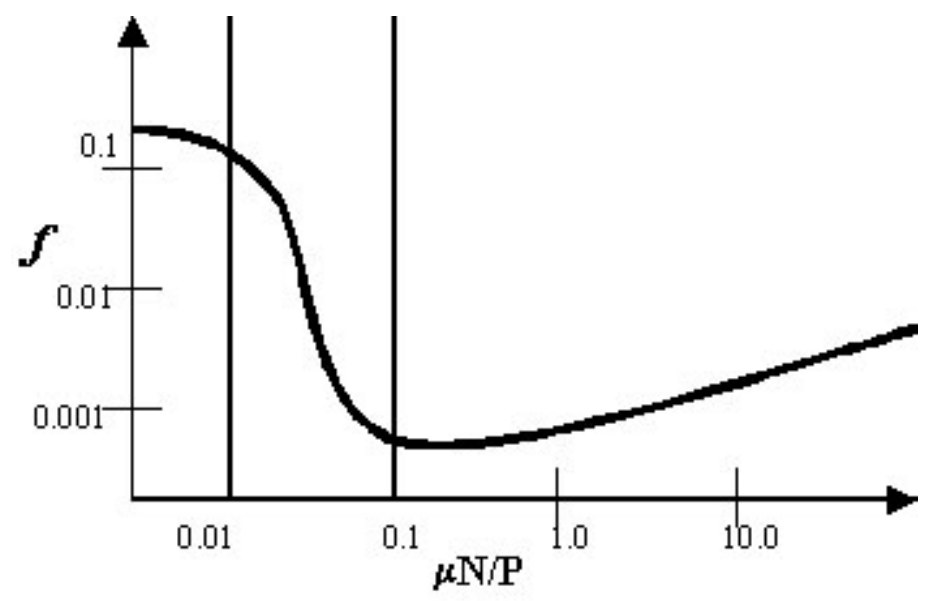

Figure 8 A Stribeck Curve [22]

It is found from calculation that for all loads and solutions tested, only the boundary lubrication and mixed hydrodynamic lubrication regimes of the Stribeck curve are relevant and there should be no chance of increasing surface friction with increasing viscosity due to fluid drag for the loads and speeds tested here. That said, Stribeck curves are concerned with systems which are predominantly 2 body (ie 2 body with a small quantity of non-intentional particles between) and the existence of a deliberate $3^{\text {rd }}$ body in the systems tested here will complicate the relationships seen in the Stribeck curve. It is interesting to note that once the wear mode transitions to 2 body wear, the applied load will be supported by a much smaller surface area of a few larger particles which separate the two surfaces and as a result the applied pressure will increase significantly which will have the effect of pushing the lubrication regime significantly leftwards in the Stribeck curve and into the boundary lubrication regime.

It can be seen for the total abrasion-corrosion plot in figure 4 that viscosity does indeed have an effect on the total wear rates by reducing friction. Soda, which has the lowest viscosity, and thus the highest surface friction values shows the highest wear rates whereas cola and orange which exhibit higher viscosities show much lower wear rates. This assumption is supported by the wear scar images in figures 7(b) and 7(d) which show far more severe wear in the soda scar than the cola scar. Milk also tends to show a slightly higher wear rate than soda and cola, however the relationship between viscosity and wear is not very linear and there are discrepancies here. It is interesting to note that the difference between cola and orange is quite significant in terms of measured viscosity however this difference is not so evident in the obtained wear rates. It is possible that cola shifts to a much higher viscosity value when exposed to high heat and pressure such as at the contact interface. It is also possible that the highly viscous constituents of colas (high fructose corn syrup) may not be removed from the contact interface as rapidly as the 
water content and gradually a highly viscous film of these constituents accumulates at the contact interface reducing friction.

To analyse the various wear regimes and transitions it is helpful to utilise the Adachi and Hutching analysis [24] for the severity of wear in each scenario. The wear severity is defined using the following formula:

$S=\frac{W}{A v H^{\prime}}$

where $\mathrm{S}$ is the severity, $\mathrm{W}$ the applied load in Newtons, A the surface area of the wear scar in $\mathrm{m}^{2}, \mathrm{v}$ the volume fraction abrasive and $\mathrm{H}^{\prime}$ which is defined using the following formula:

$\frac{1}{H^{\prime}}=\frac{1}{H s}+\frac{1}{H b}$

where $\mathrm{Hs}$ is the hardness of the test specimen and $\mathrm{Hb}$ is the hardness of the counterface ball. The following map (figure 9) from a recent paper [25] by J Bello et al summarises the relationship between severity and hardness ratio which was discovered by Adachi and Hutchings [24].

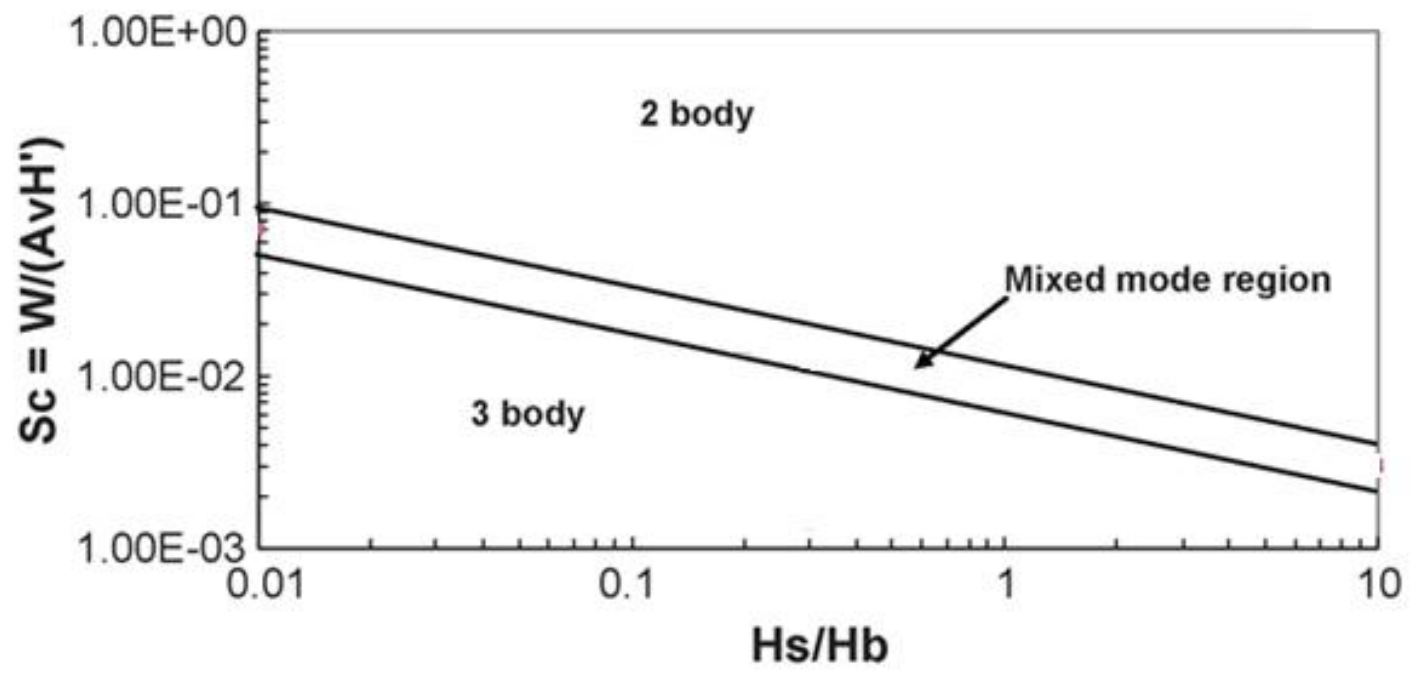

Figure 9[25]

In all experiments tried in this paper the value of $\mathrm{Hs} / \mathrm{Hb} \approx 0.5$. Figure 10 shows a plot of the various severity values obtained for each solution at each load. In general it can be summarised that increases in severity push the wear mode toward the 2 body region whilst decreases result in the wear mode moving toward a 3 body regime. 


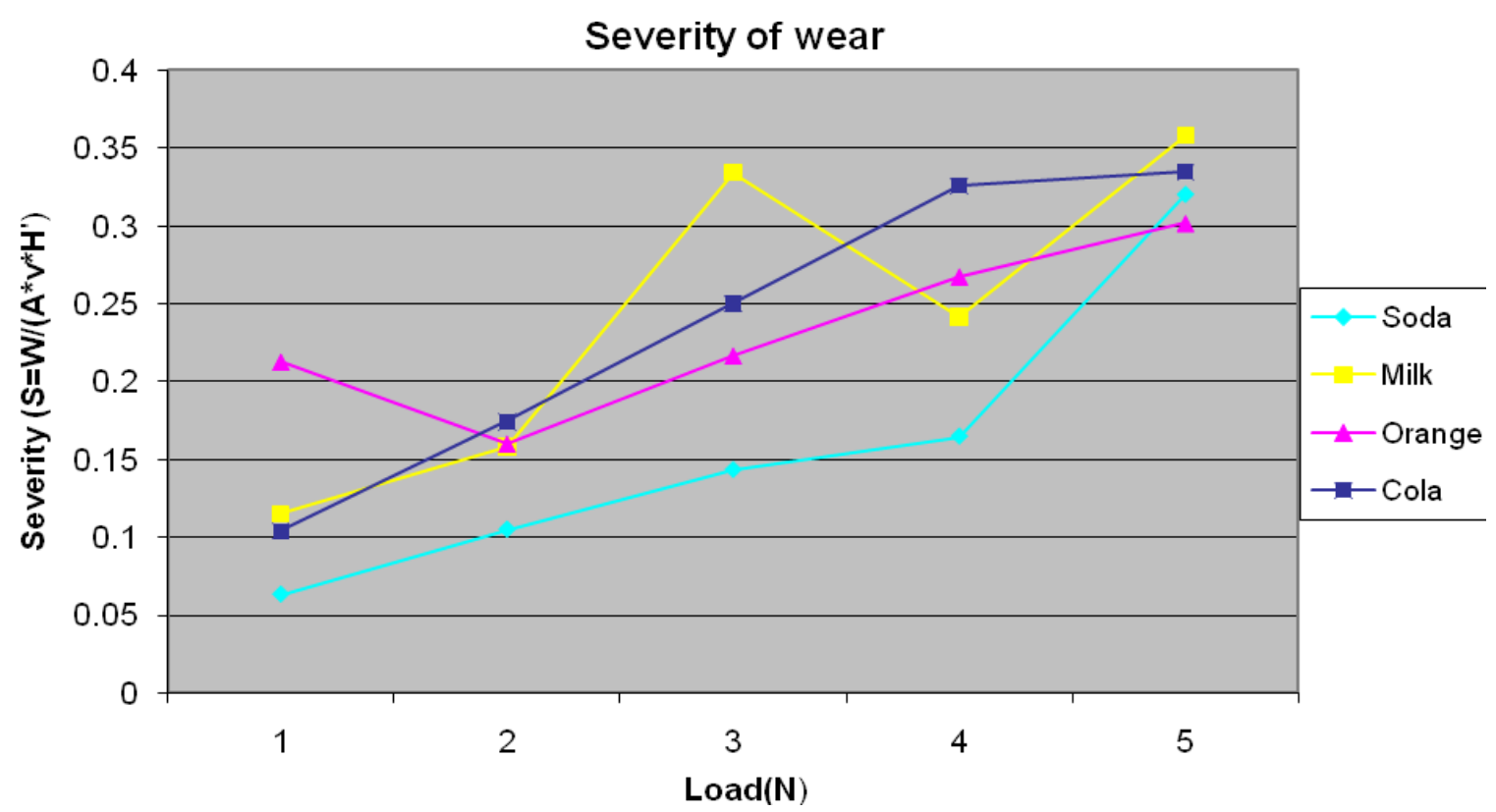

Figure 10

To further aid in the analysis it is helpful to consider the wear mode groupings developed by Stack et al [26]. The wear mode groups are summarized as the following:

(i) 3-2 body: gradual increase in wear volume with applied load. Sub-regimes are

(a) Particles rolling between surfaces.

(b) Grooving as a result of particle adhesion to the counterbody.

(c) Mixed combination of $a$ and $b$.

(ii) 2 body-r reduction of wear volume as a function of applied load. Sub-regimes are

(a) Particles become lost in the grooves/ridges produced by (i) $b$. The asperities of the sample and countersurface come into contact and a 2 body process proceeds.

(b) Frictional heat generated by the 2 body process in part (a) results in rapid oxidation of the contact surface.

For all solutions tested there is a general increase in wear rate with applied load in accordance with the Archard law [15] between 1- 4N with the exception of milk which shows different behaviour (figure5). Figures 9-10 as well the mode grouping table by Stack [26] indicate that for all solutions except milk the wear mode is 2 body grooving between 1 and $4 \mathrm{~N}$. The exception to this rule is orange at $1 \mathrm{~N}$ and $2 \mathrm{~N}$ which may exist in the mixed regime on figure 9 . This is a valid hypothesis as the original map in figure 9 was developed for tribo-corrosion of steel in pure water which has a lower viscosity than orange. It is therefore possible that the slightly higher viscosity orange which has a greater lubricating effect could extend the mixed mode region and incorporate the wear severity of orange at $1 \mathrm{~N}$ and $2 \mathrm{~N}$. This would explain how at low loads the wear mode can 
transition in orange from a 2 body severity to a lower severity 3 body mode. At intermediate loads the orange is likely to move into a 2 body grooving regime due to increasing severity.

At higher loads there is an obvious transition to 2 body ridging/oxidative wear in the Soda and this may occur at intermediate loads depending on the regions of the error bars at each load which are selected. The transition to 2 body ridging in cola and orange at higher loads is not quite as obvious and again depending on the regions of the error bars which are selected at each load, a transition to 2 body ridging may not occur at all for these solutions in the load range tested. This observation would be in correlation with the earlier prediction that a transition to a 2 body ridging mode would occur at higher loads in more viscous solutions due to the relationship $(\mathrm{D} / \mathrm{h})[23]$.

The corrosive wear rates (figure 3 ) in all solutions except milk follow a similar trend which is to increase sharply between $1 \mathrm{~N}$ and $2 \mathrm{~N}$ then a much smaller increase between $2 \mathrm{~N}$ and $4 \mathrm{~N}$ (corresponding to an increase in wear severity which is 2 body dominated), followed by a decrease in corrosive wear rate between $4 \mathrm{~N}$ and $5 \mathrm{~N}$ for all solutions except milk. The change in corrosive wear rate at intermediate loads is likely to be due to the formation of passive films due to higher loading and more surface heat/oxidation. At intermediate loads from $2 \mathrm{~N}-4 \mathrm{~N}$, the formation of these films is almost balanced by the increased removal of the films due to higher loading and there is little difference in the corrosion rate with increased applied load. At higher loads, however, oxidative wear predominates which corresponds with a change in mechanical wear mode as described above and the corrosion current drops significantly due to resistance from thick oxide layers. It is interesting to note however that the evidence of oxidative wear in the corrosion wear rates (figure 3 ) for orange and cola at $5 \mathrm{~N}$ is not supported by an obvious change in mechanical wear mode. It is possible that in orange and cola at $5 \mathrm{~N}$ the wear mode is indeed ridging/oxidation dominated; however, the oxide layer is not fully cohesive yet which contributes to an increase in mechanical wear rate seen in figure 5 .

Finally, it should be noted that the increase in corrosive wear rate (figure 3 ) between 2 and $4 \mathrm{~N}$ is greater in orange than in soda and cola. This is attributed to a greater reduction in lubricating film thickness with applied loading which reduces the system resistance and increases corrosion current [27]. The unloaded film thicknesses of soda and cola are smaller and thus the decreases in film thickness with applied loading are less significant.

For milk, there is a similar situation to the other solutions. However, the transition to 2 body ridging wear occurs at $3 \mathrm{~N}$ which is $1 \mathrm{~N}$ lower than any evidence of a transition to 2 body ridging wear in soda (figure 5). This is interesting as the milk has a slightly higher viscosity than soda and going on the relation between $(\mathrm{D} / \mathrm{h})$ alone $[23]$, the milk should transition at a higher load than soda. This transition is supported by a peak in severity at $3 \mathrm{~N}$ on figure 10 . A number of variables including $\mathrm{pH}$, viscosity and the presence of gas bubbles may account for the transition at higher loads in soda. Above $3 \mathrm{~N}$, there is a likely increase in wear rate over the remaining increases in loads due to a transition back to 2 body grooving which is within the error bars (figure3) and corresponds to a gradual increase in corrosive wear rate (figure 5) due to the removal of passive film. 


\section{$\underline{\text { Maps }}$}

A standard procedure in the mapping of micro-abrasion corrosion is to produce different maps of mechanisms, wastage and tribo-corrosive synergy. The regimes used in the production of these maps have been taken from various papers completed by Stack et al $[9-11,28]$. The information used to construct these tables can be found in Appendices 13.

The regimes for the mechanism map are as follows:
$\mathrm{Kc} / \mathrm{Ka} \leq 0.1$
micro-abrasion
$0.1<\mathrm{Kc} / \mathrm{Ka} \leq 1$
micro-abrasion- corrosion
$1<\mathrm{Kc} / \mathrm{Ka} \leq 10$
corrosion -micro-abrasion
$\mathrm{Kc} / \mathrm{Ka}>10$
corrosion

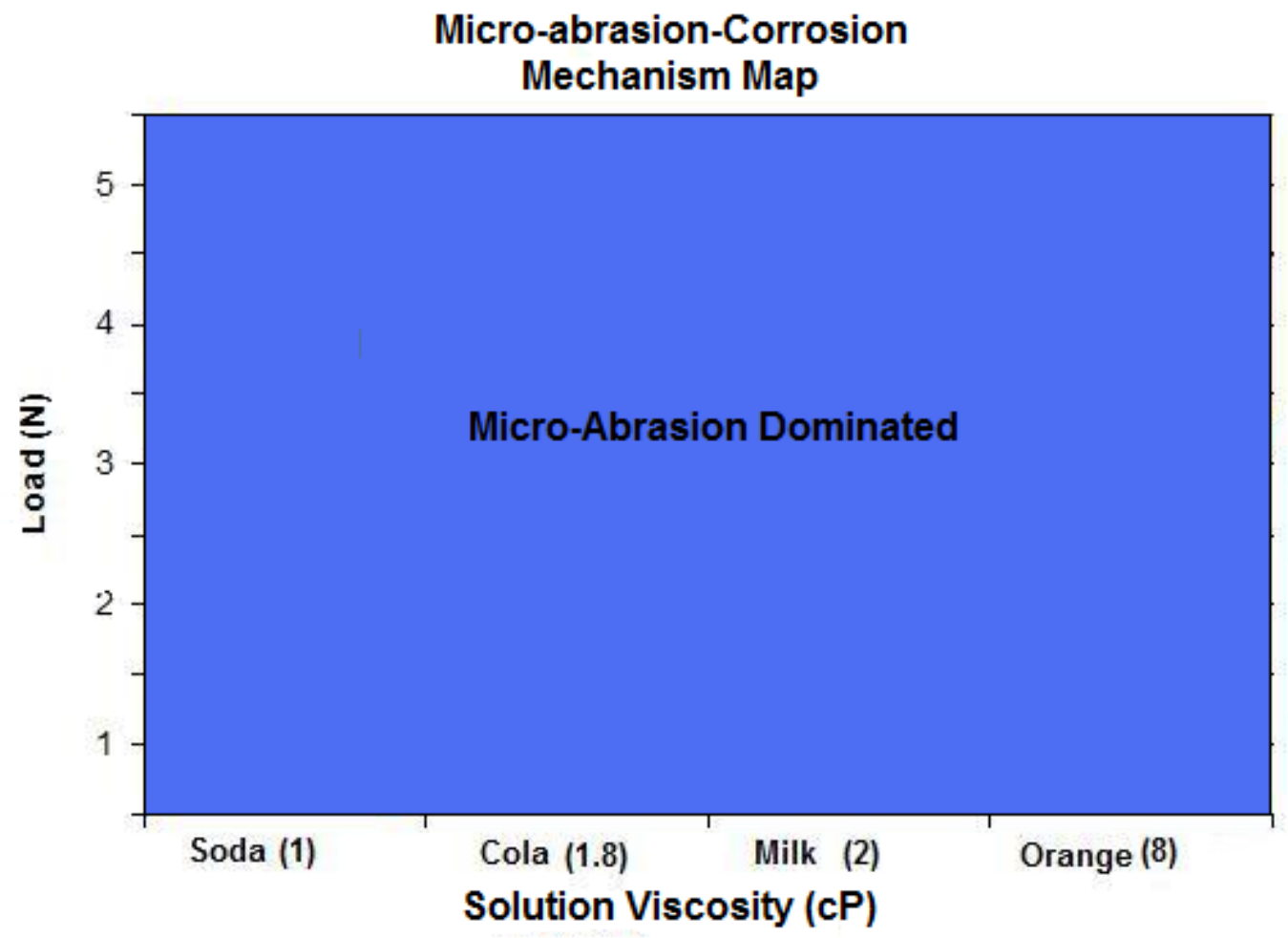

Figure 11 Mechanism Map

As previously stated the mechanical wear rates in all experiments were much larger than the corrosion wear rates and as a result the entire mechanism map (figure 11) is found to be micro-abrasion dominated. 
The wastage map regimes from [9] have been modified by a factor of 0.4 which takes into account the shorter sliding distance in this paper. The Regimes are:

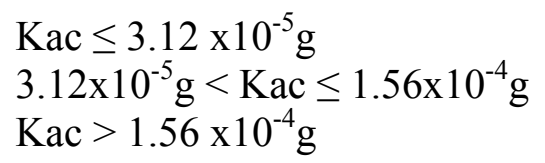

Low Wastage

Medium Wastage

High Wastage

The wastage map for this work is shown in figure 12

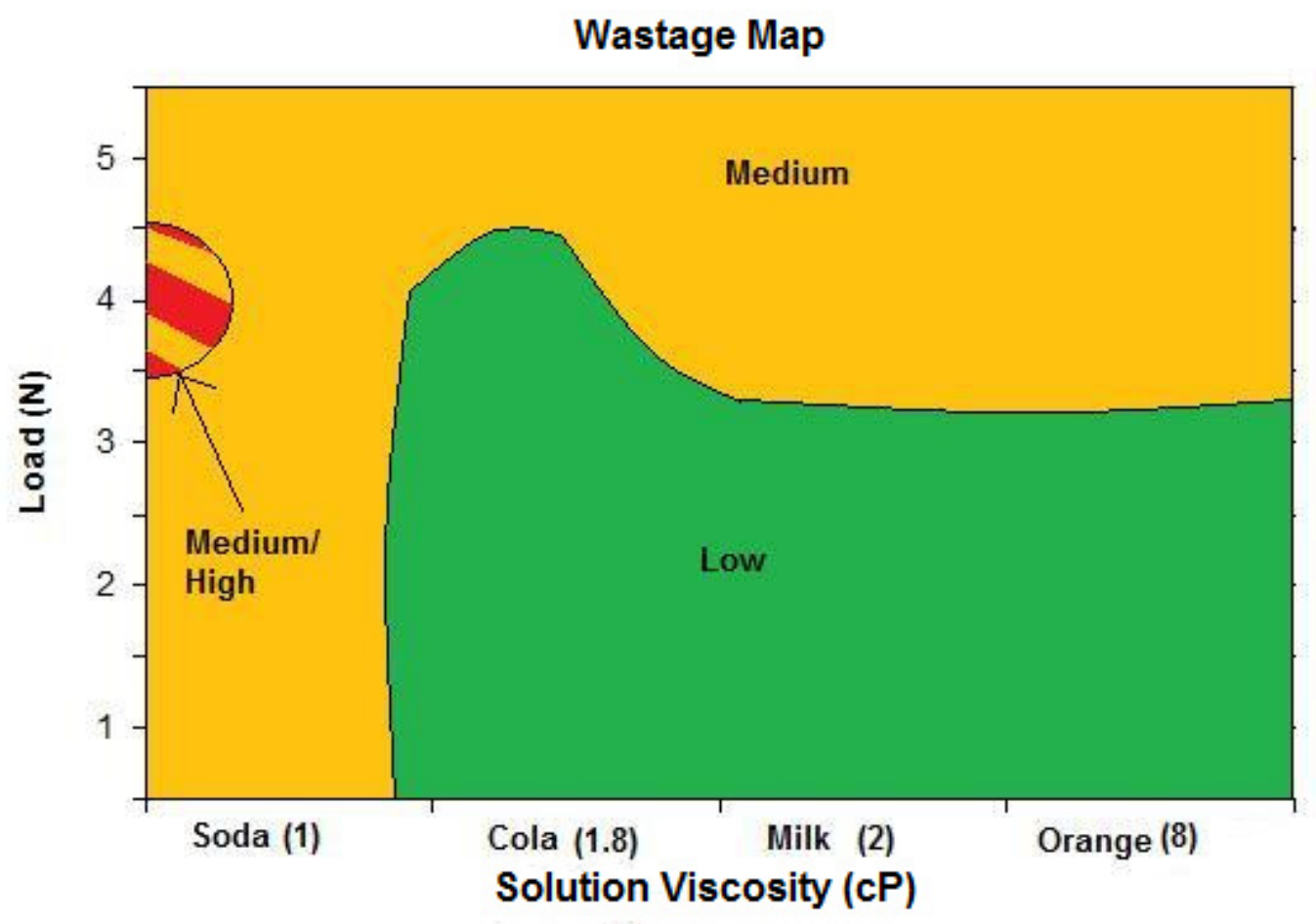

Figure 12 Wastage Map (Load versus Viscosity)

It was determined from experimental results that there is a much more significant relationship between total losses and solution viscosity as opposed to solution $\mathrm{pH}$. From figure 12 it can be seen that the lowest wastages occur at low loads and high viscosity. Interestingly cola shows lower wastage for a greater range of loads than milk and orange despite its lower viscosity. This may be attributed to the accumulation of highly viscous constituents which are not fully represented in rheological experiments for cola. Additionally there is a notable lower material loss at $5 \mathrm{~N}$ in soda than at $4 \mathrm{~N}$. This will likely be due to oxidative and 2 body ridging effects. Figure 13 shows another version of the map with load versus $\mathrm{pH}$ plotted. 


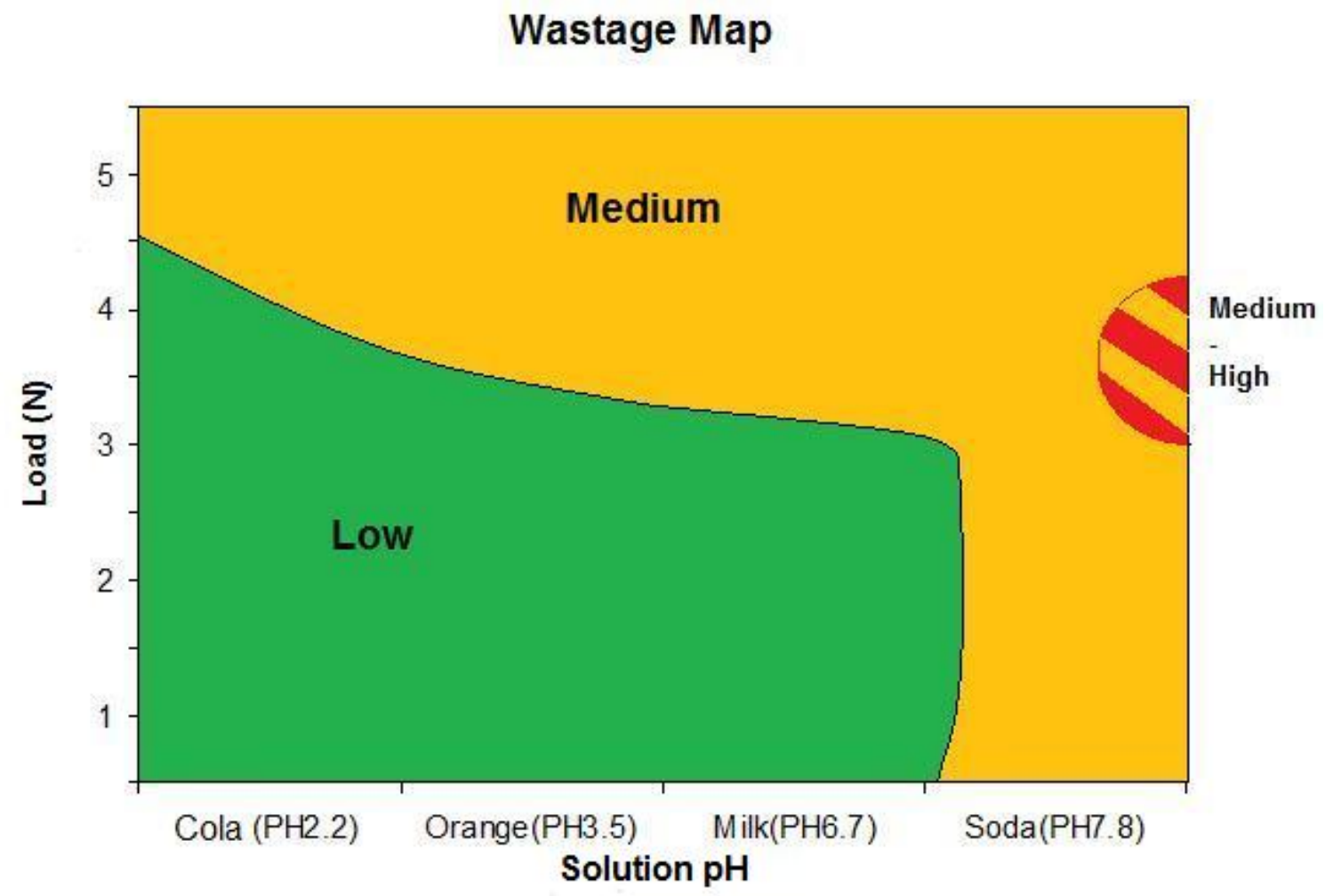

Figure 13 Wastage Map (Load versus PH)

For the abrasion-corrosion synergy map the following regimes were used [28]

$\begin{array}{ll}\Delta \mathrm{Ka} / \mathrm{Kao} \leq 1 & \text { Low Synergy } \\ 1<\Delta \mathrm{Ka} / \mathrm{Kao} \leq 10 & \text { Medium Synergy } \\ \Delta \mathrm{Ka} / \Delta \mathrm{Kc}>10 & \text { High Synergy } \\ & \\ \Delta \mathrm{Ka} / \mathrm{Kao} \geq-1 & \text { Low Antagonism } \\ -1>\Delta \mathrm{Ka} / \mathrm{Kao} \geq-10 & \text { Medium Antagonism } \\ \Delta \mathrm{Ka} / \mathrm{Kao}<-10 & \text { High Antagonism }\end{array}$

Additionally a $7^{\text {th }}$ regime was defined as the transition regime. After examining the experimental errors and varying values of Ka by the experimental error $\pm 18.75 \%$ the transition regime is defined as any part of the map which can change sign from synergy to antagonism on varying the value of Ka through the extremes of its error. This regime is useful as it separates extreme gradients between synergy and antagonism and tends to occur between the borders of these two regimes on maps which consider the most important variables. The abrasion-corrosion synergy map is shown in figure 14. 


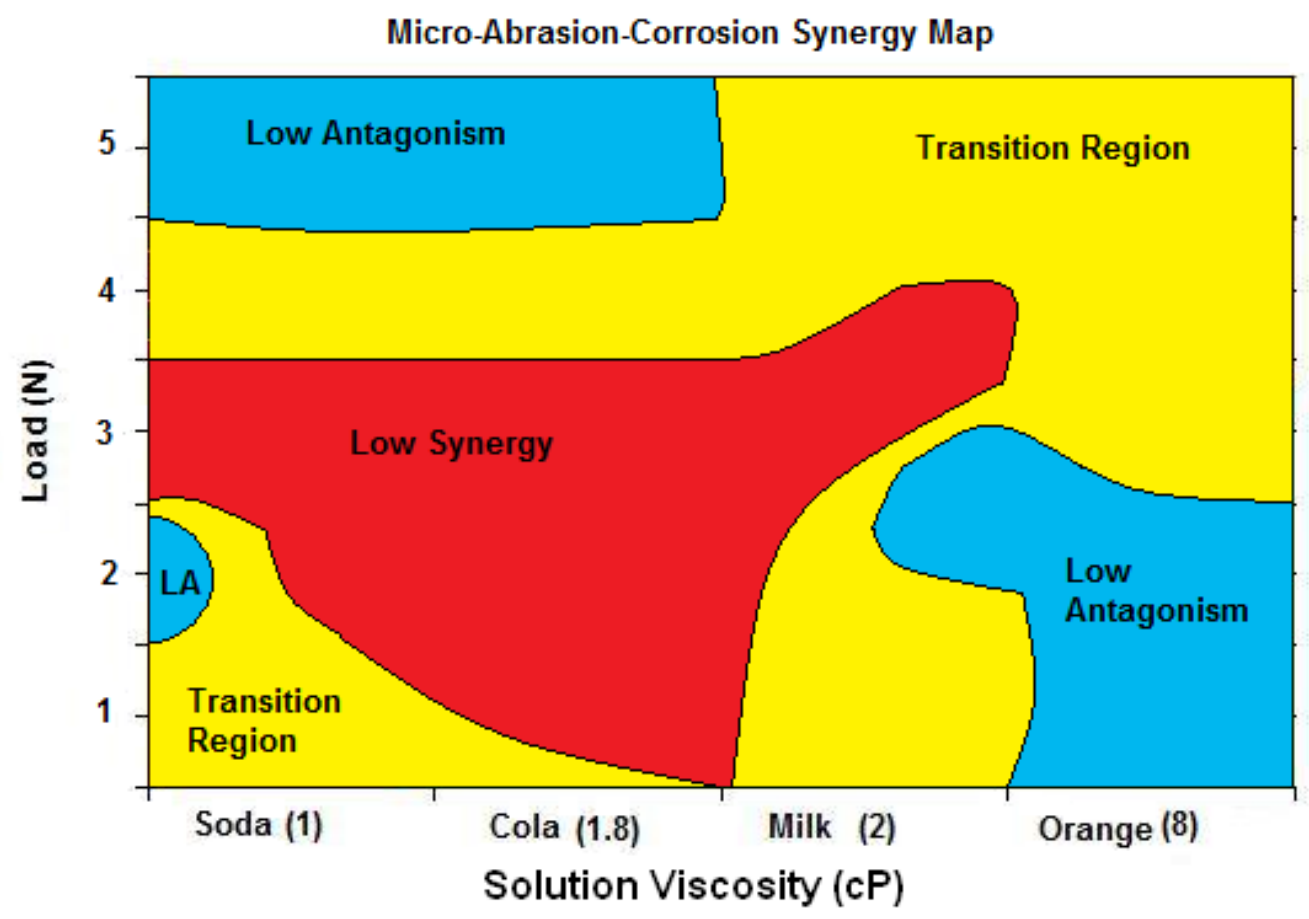

Figure 14 Synergy Map (Load versus Viscosity)

It can be seen that medium loads and higher viscosities produce synergistic conditions whilst combinations of either high loads and low viscosities or low loads and high viscosities produce antagonistic conditions. An analysis of the various contributions to the synergy map showed that the additive effect (corrosion enhanced by abrasion) was only significant for milk at $1 \mathrm{~N}$ whilst the rest of the map was dominated by the synergistic effect (abrasion enhanced by corrosion).

It is interesting to note that at low loads and viscosities there is no definite regime and a large transition region exists. However it should be remembered that the lowest loads produced the smallest readings and as such these measurements were most sensitive to experimental error. (It is possible that more thorough investigation is required in the transition regions of figure 14 as they do not show an obvious bias towards either synergy or antagonism). An additional synergy map of load versus $\mathrm{pH}$ was produced during this work and can be seen in figure 15 . This indicates, that although viscosity tends to show a clearer relationship in determining synergy at certain load scenarios as shown above, the effect of $\mathrm{pH}$ in determining the synergy/antagonistic transitions is less clear. Further work will be required to assess this relationship in more detail. 


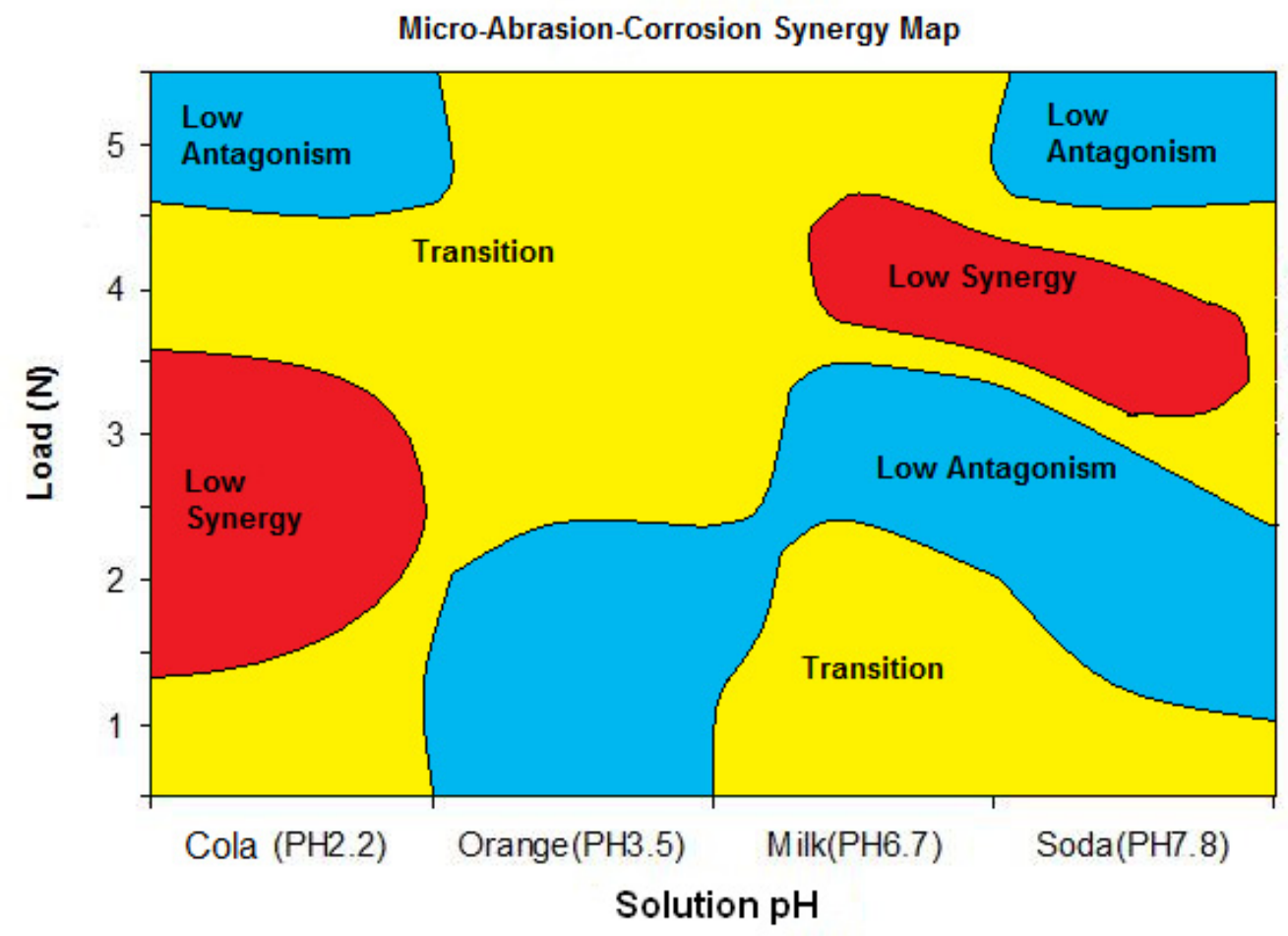

Figure 15 Synergy Map (Load versus pH)

It can be hypothesised that both milk and soda experience antagonistic and transition regimes for the majority of loads tested due to the formation of protective passive films in the anodic regime. However, Pourbaix diagrams for steel indicate that exposure to orange and cola should result in dissolution in the anodic regime over the potentials tested and antagonistic behaviour cannot be attributed to passive film formation. Additionally, the presence of synergy regimes at 3 and $4 \mathrm{~N}$ for Soda and Milk respectively indicate that some other variable is playing an important role which is likely to be solution viscosity. It is possible that corroded metals ions may alter the solution viscosity which will in turn have an effect on the contact friction coefficient. It is also possible that the formation of passive films and corroded surfaces will alter the surface roughness which has been shown to be an important factor in determining the surface friction coefficient [29]. It is impossible to say how corrosion affects solution viscosity at the moment and important further work will be to look at the synergy relationship under more controlled conditions (ie constant $\mathrm{pH}$ ).

Hence, the above research indicates that the tribo-corrosion behaviour of stainless steel in soft drinks is more complex than originally perceived due to the differential effects of solution viscosity on the degradation rate. The results have provided a means of generating novel micro-abrasion corrosion maps indicating mechanism of wastage and levels of synergy/antagonism as a function of load, $\mathrm{pH}$ and solution viscosity. Further work will be to addresses the areas above in addition to considering the performance of other replacement materials in such conditions. 


\section{Conclusions}

(i) An attempt has been made to document the tribo-corrosive wear regimes which are encountered by Stainless Steel dental materials during exposure to common drinks. It has been found that a complex relationship exists between the total wear rates and the solution $\mathrm{pH}$, viscosity and the applied loading.

(ii) In all experiments the majority of weight loss can be attributed to mechanical wear which in most cases is several hundred times greater than electrochemical wear. As such the influence of viscosity tends to dominate as it has been shown to have the effect of decreasing surface friction via lubricating films which reduces the overall mechanical wear. The solution $\mathrm{pH}$ has a diminished role due to the low corrosion rates and it appears that the corrosion rates in abrasion - corrosion are more influenced by solution viscosity than $\mathrm{pH}$.

(iii) Wastage maps as well as abrasion-corrosion synergy maps have been plotted to further illustrate and explain the results obtained. It was found that both viscosity and solution $\mathrm{pH}$ play important roles in determining the tribocorrosive synergy regimes and further work is required to separate the effect of each variable.

\section{$\underline{\text { Acknowledgements }}$}

The authors wish to thank EPSRC for the award of a vacation scholarship to Christopher Hodge to carry out the initial work on this project during the summer of 2009. They also wish to acknowledge the University of Strathclyde for the award of the EPSRC vacation student prize for the initial work on this project.

\section{$\underline{\text { References }}$}

[1] W.M. Elshahawy, I. Watanabe, P. Kramer., 2009. In vitro cytotoxicity evaluation of elemental ions released from different prosthodontic materials. Dental materials,25(12), pp 1551-1555.

[2] R. Lewis, R.S. Dwyer-Joyce., 2005. Wear of human teeth: a tribological perspective. Proc. Inst. Mech. Eng. J: J. Eng. Tribol. 219 1-18

[3] Z.R. Zhou, J. Zheng., 2007. Tribology of dental materials: a review. Journal of Physics D-Applied Physics, 41(11), 113001 (pp 22).

[4] MM Stack, J Jirka, MT Matthew, H Jawan., (In Press) Micro-abrasion-corrosion of a $\mathrm{Co}-\mathrm{Cr} / \mathrm{UHMWPE}$ couples in Ringer's solution: an approach to construction of mechanism and synergism maps for applications to bio implants (Accepted April 2010). [5] P.E. Sinnett-Jones, J.A. Wharton, R.J.K. Wood., 2005. Micro-abrasion-corrosion of a CoCrMo alloy in simulated artificial hip joint environments. Wear 259(Part 2 Sp. Iss. SI),pp 898-909. 
[6] M.T. Matthew, M.M. Stack., 2004, Micro-abrasion interactions of pure metals in Biooils. J.Synthetic Lubrication, 21(2), pp105-117.

[7] D. Sun, J.A.Wharton, R.J.K.Wood , L.Ma, W.M. Rainforth., 2008. Microabrasioncorrosion of cast CoCrMo alloy in simulated body fluids. Tribology Int,42(1), pp 99-110. [8] M. Favero, P. Stadelmann, S. Mischler., 2006. J Phys D: Appl Phys 2006;39:317583.

[9] M.M. Stack, H. Jawan, M.T. Mathew., 2005. On the construction of micro-abrasion maps for a steel/polymer couple in corrosive environments. Tribology Int,38(9) pp848-56 [10] M.T. Mathew, M.M. Stack, B. Matijevic, L.A. Rocha, E. Ariza., 2007. Microabrasion resistance of thermochemically treated steels in aqueous solutions: Mechanisms, maps, materials selection. Tribology Int, 41(2), pp141-9.

[11] M.M. Stack, M.T. Mathew., 2003 Mapping the micro-abrasion resistance of WC/Co based coatings in aqueous conditions. Surface\&Coatings Technology, 183(2-3), pp33746.

[12] K.L. Rutherford, I.M. Hutchings., 1997. Journal of Test Eval. JTEVA 1997;25(2): 250-60.

[13] Z. Yue, P. Zhou, J. Shi., 1987. In: Luedema KC, editor. Proceedings of conference on wear of materials. New York: ASME;1987.p.763-8.

[14] S. Akonko, D.Y. Li, M. Ziomek-Moroz.,2005. Tribol Lett 2005;18:405-10.

[15] J.F. Archard., 1953. Contact and rubbing of flat surfaces. J Appl.Phys.24 (1953) 981.

[16] S. Kalpakjian., 1991. Manufacuturing Processes for Engineering Materials second edition, Addison- Weasley, Reading, MA.

[17] US Department of Energy, January 1993 DOE Fundamentals Handbook Chemistry Volume 1 of 2 figure 7 page 117 Knowledge Publications.

[18] M. Pourbaix, 1974. Atlas of Electrochemical equilibria in aqueous solutions $2^{\text {nd }}$ ed Houston, Tex. :National Association of Corrosion Engineers.

[19]Michael Smith Engineers Ltd Viscosities of common liquids (Table) [Online] Available at:

http://www.michaelsmithengineers.co.uk/pdfs/ViscositiesofCommonLiquids2.pdf [Accessed 17th May 2010]

[20] S. M. Kappes, S. J. Schmidt, S.Y. Lee., 2006. Journal Of Food Science -Vol. 71, Nr. 9.

[21] B. Rega, N. Fournier, S. Nicklaus, and E. Guichard., 2004. J. Agric. Food Chem. 2004, 52, 4204-4212.

[22] Society of Tribologists and Lubrication Engineers, Basics of Lubrication [Online] (Updated 2008) Available at:

http://www.stle.org/resources/lubelearn/lubrication/default.aspx [Accessed 17th May 2010]

[23] J.A. Williams A.M. Hyncica., 1992. Mechanisms of Abrasive wear in lubricated contacts. Wear ,152(1), pp 57-74.

[24] K. Adachi, I.M. Hutchings., 2003. Wear-mode mapping for the micro-scale abrasion test. Wear 255, pp23-29.

[25] J.O. Bello , R.J.K. Wood, J.A.Wharton., 2007. Synergistic effects of microabrasion-corrosion of UNS S30403, S31603 and S32760 stainless steels. Wear, 263 (2007) pp 149-159. 
[26] M.M. Stack, M.T. Mathew., 2003. Micro-abrasion transitions of metallic materials. Wear, 255 (2003) pp14-22.

[27] R.M. Crockett, M.P. Derendinger, P.L. Hug, S. Roos., 2004. Wear and electrical resistance on diesel lubricated surfaces undergoing reciprocating sliding. Tribology Letters, 16(3), pp 187-194.

[28] M.M. Stack, T.M. Abd El Badia., 2006. On the construction of erosion-corrosion maps for WC/Co-Cr based coatings in aqueous conditions. Wear, 261(11-12), pp1181-90. [29] M.M. Maru, D.K. Tanaka., 2007. Consideration of Stribeck Diagram Parameters in the Investigation on Wear and Friction Behavior in Lubricated Sliding. J. of the Braz. Soc. of Mech. Sci. \& Eng, 29(1), pp55-62. 


\section{Appendix 1}

\begin{tabular}{|c|c|c|c|c|c|}
\hline Load $(\mathrm{N})$ & $\operatorname{Kac}\left(\operatorname{gx} 10^{-3}\right)$ & $\mathrm{Kc}\left(\mathrm{g} \times 10^{-3}\right)$ & $\mathrm{Ka}\left(\mathrm{g} \times 10^{-3}\right)$ & $\mathrm{Ka} / \mathrm{Kc}$ & Mechanism \\
\hline \multicolumn{5}{|l|}{ (a)Cola } & \\
\hline 1 & 0.014 & $3.77 \times 10^{-5}$ & 0.014 & 0.0026 & \multirow{5}{*}{$\begin{array}{l}\text { Micro- } \\
\text { abrasion } \\
\text { dominated }\end{array}$} \\
\hline 2 & 0.021 & $4.78 \times 10^{-5}$ & 0.020 & 0.0023 & \\
\hline 3 & 0.022 & $4.52 \times 10^{-5}$ & 0.022 & 0.0020 & \\
\hline 4 & 0.025 & $4.61 \times 10^{-5}$ & 0.024 & 0.0019 & \\
\hline 5 & 0.035 & $3.93 \times 10^{-5}$ & 0.034 & 0.0011 & \\
\hline \multicolumn{5}{|c|}{ (b) Orange } & \\
\hline 1 & 0.007 & $6.98 \times 10^{-5}$ & 0.006 & 0.0011 & \multirow{5}{*}{$\begin{array}{l}\text { Micro- } \\
\text { abrasion } \\
\text { dominated }\end{array}$} \\
\hline 2 & 0.025 & $10.26 \times 10^{-5}$ & 0.024 & 0.0042 & \\
\hline 3 & 0.030 & $9.99 \times 10^{-5}$ & 0.029 & 0.0034 & \\
\hline 4 & 0.035 & $11.95 \times 10^{-5}$ & 0.034 & 0.0034 & \\
\hline 5 & 0.043 & $10.52 \times 10^{-5}$ & 0.043 & 0.0024 & \\
\hline \multicolumn{5}{|l|}{ (c) Milk } & \\
\hline 1 & 0.012 & $11.27 \times 10^{-5}$ & 0.011 & 0.0097 & \multirow{5}{*}{$\begin{array}{l}\text { Micro- } \\
\text { abrasion } \\
\text { dominated }\end{array}$} \\
\hline 2 & 0.025 & $8.56 \times 10^{-5}$ & 0.025 & 0.0034 & \\
\hline 3 & 0.013 & $7.98 \times 10^{-5}$ & 0.012 & 0.0063 & \\
\hline 4 & 0.049 & $8.51 \times 10^{-5}$ & 0.049 & 0.0017 & \\
\hline 5 & 0.030 & $14.48 \times 10^{-5}$ & 0.030 & 0.0048 & \\
\hline \multicolumn{5}{|l|}{ (d) Soda } & \\
\hline 1 & 0.039 & $2.89 \times 10^{-5}$ & 0.039 & 0.00074 & \multirow{5}{*}{$\begin{array}{l}\text { Micro- } \\
\text { abrasion } \\
\text { dominated }\end{array}$} \\
\hline 2 & 0.057 & $3.70 \times 10^{-5}$ & 0.056 & 0.00065 & \\
\hline 3 & 0.073 & $3.90 \times 10^{-5}$ & 0.073 & 0.00053 & \\
\hline 4 & 0.092 & $3.87 \times 10^{-5}$ & 0.092 & 0.00042 & \\
\hline 5 & 0.038 & $3.15 \times 10^{-5}$ & 0.037 & 0.00083 & \\
\hline
\end{tabular}




\section{Appendix 2}

\begin{tabular}{|l|l|l|l|l|}
\hline Load $(\mathrm{N})$ & $\Delta \mathrm{Ka}\left(\mathrm{gx} 10^{-3}\right)$ & $\mathrm{Kao}\left(\mathrm{gx} 10^{-3}\right)$ & $\Delta \mathrm{Ka} / \mathrm{KaO}$ & Effect \\
\hline \begin{tabular}{l}
$\mid \mathrm{a})$ Cola \\
\hline 1
\end{tabular} & 0.0016 & 0.0128 & 0.125 & Low synergism \\
\hline 2 & 0.0087 & 0.0119 & 0.728 & Low synergism \\
\hline 3 & 0.0046 & 0.0177 & 0.260 & Low synergism \\
\hline 4 & -0.0015 & 0.0263 & -0.057 & Low antagonism \\
\hline 5 & -0.0142 & 0.0491 & -0.290 & Low antagonism \\
\hline (b) Orange & 0.0110 & 0.0174 & -0.626 & Low antagonism \\
\hline 1 & -0.0078 & 0.0322 & -0.243 & Low antagonism \\
\hline 2 & 0.0013 & 0.0285 & 0.046 & Low synergism \\
\hline 3 & -0.0049 & 0.0396 & -0.123 & Low antagonism \\
\hline 4 & 0.0030 & 0.0400 & 0.075 & Low synergism \\
\hline 5 & 0.0007 & 0.0109 & 0.067 & Low synergism \\
\hline$(\mathrm{c})$ Milk & 0.0022 & 0.0228 & 0.098 & Low synergism \\
\hline 1 & -0.0071 & 0.0198 & -0.361 & Low antagonism \\
\hline 2 & 0.0184 & 0.0307 & 0.597 & Low synergism \\
\hline 3 & $-7.55 \times 10^{-5}$ & 0.0303 & -0.002 & Low antagonism \\
\hline 4 & \multicolumn{5}{|l}{} \\
\hline 5 & 0.0047 & 0.0343 & 0.136 & Low synergism \\
\hline$(\mathrm{d})$ Soda & -0.0172 & 0.0738 & -0.233 & Low antagonism \\
\hline 1 & 0.0309 & 0.0422 & 0.731 & Low synergism \\
\hline 2 & 0.0122 & 0.0801 & 0.152 & Low synergism \\
\hline 3 & -0.0426 & 0.0805 & -0.529 & Low antagonism \\
\hline 4 &
\end{tabular}




\section{Appendix 3}

\begin{tabular}{|c|c|c|c|c|}
\hline Load (N) & $\Delta \mathrm{Ka}\left(\mathrm{g} \times 10^{-3}\right)$ & $\Delta \mathrm{Kc}\left(\mathrm{g} \times 10^{-3}\right)$ & $\Delta \mathrm{Ka} / \Delta \mathrm{Kc}$ & $\begin{array}{l}\text { Contributing } \\
\text { effect }\end{array}$ \\
\hline \multicolumn{5}{|l|}{ (a)Cola } \\
\hline 1 & 0.0016 & $0.43 \times 10^{-5}$ & 374.46 & Synergy \\
\hline 2 & 0.0087 & $1.44 \times 10^{-5}$ & 603.11 & Synergy \\
\hline 3 & 0.0046 & $1.17 \times 10^{-5}$ & 393.20 & Synergy \\
\hline 4 & -0.0015 & $1.26 \times 10^{-5}$ & -118.78 & Antagonistic \\
\hline 5 & -0.0142 & $0.59 \times 10^{-5}$ & -2420.88 & Antagonistic \\
\hline \multicolumn{5}{|c|}{ (b) Orange } \\
\hline 1 & 0.0110 & $4.01 \times 10^{-5}$ & -271.95 & Antagonistic \\
\hline 2 & -0.0078 & $7.28 \times 10^{-5}$ & -107.59 & Antagonistic \\
\hline 3 & 0.0013 & $7.02 \times 10^{-5}$ & 18.73 & Synergy \\
\hline 4 & -0.0049 & $8.98 \times 10^{-5}$ & -54.27 & Antagonistic \\
\hline 5 & 0.0030 & $7.55 \times 10^{-5}$ & 39.62 & \begin{tabular}{|l|} 
Synergy \\
\end{tabular} \\
\hline \multicolumn{5}{|l|}{ (c) Milk } \\
\hline 1 & 0.0007 & $9.71 \times 10^{-5}$ & 7.53 & Synergy \\
\hline 2 & 0.0022 & $6.99 \times 10^{-5}$ & 32.02 & Synergy \\
\hline 3 & -0.0071 & $6.42 \times 10^{-5}$ & -111.28 & Antagonistic \\
\hline 4 & 0.0184 & $6.94 \times 10^{-5}$ & 264.34 & Synergy \\
\hline 5 & $-7.55 \times 10^{-5}$ & $12.92 \times 10^{-5}$ & -0.58 & $\begin{array}{l}\text { Additive- } \\
\text { Antagonistic }\end{array}$ \\
\hline \multicolumn{5}{|l|}{ (d) Soda } \\
\hline 1 & 0.0047 & $0.47 \times 10^{-5}$ & 991.75 & Synergy \\
\hline 2 & -0.0172 & $1.29 \times 10^{-5}$ & -1339.83 & Antagonistic \\
\hline 3 & 0.0309 & $1.48 \times 10^{-5}$ & 2080.21 & Synergy \\
\hline 4 & 0.0122 & $1.46 \times 10^{-5}$ & 836.98 & Synergy \\
\hline 5 & -0.0426 & $0.74 \times 10^{-5}$ & -5792.23 & Antagonistic \\
\hline
\end{tabular}

